REVISTA DE DERECHO UNED, NÚM. 17, 2015

\title{
EL CONSENTIMIENTO INFORMADO EN ANESTESIOLOGÍA
}

\author{
INFORMED CONSENT IN ANESTHESIOLOGY
}

Alfonso Serrano GiL

Profesor Ayudante Departamento Derecho Civil

Resumen: La anestesiología como especialidad médica no tiene por sí misma un gran recorrido histórico, pero durante las últimas décadas se ha desarrollado como un campo independiente en la medicina. En el trasfondo de esta especialidad subyace una diferencia fáctica determinante con la medicina estrictamente concebida. Mientras que esta última tiene por destino curar o restaurar la salud de paciente, la anestesiología no provee una solución a la enfermedad, sino tan solo un método para evitar el sufrimiento y, simultáneamente, ayudar a los procedimientos quirúrgicos o pruebas médicas a ser practicadas sin la oposición del paciente, lo que subsecuentemente puede dirigir a mejores resultados curativos. En este sentido, el consentimiento que presta el paciente debe ser dual. De una parte al cirujano que practica la intervención o al médico que realiza la técnica, y por otra parte al anestesista que va a intervenir en el acto anestésico. Respecto a la información ocurre exactamente igual. El anestesista debe informar sobre las ventajas y los inconvenientes y las distintas alternativas del tratamiento anestésico, ya que por muy banal que sea la intervención o técnica a practicar, la anestesia siempre conlleva riesgos para el paciente.

Abstract: Anesthesiology as a medical specialty has little history background as itself, but over the last decades has rapidly developed into an entire and independent medical field. In the bottom of this specialty lies a factual and determinant difference with medicine strictly conceived. While the latter is meant to cure or restore the 
health of the patient, anesthesiology doesn't actually provide a solution for illness, but just a method to avoid the suffering and, simultaneously, help surgery procedures or medical tests to be practiced without opposition from the patient, which may subsequently lead to better curing results. Therefore, consent provided by the patient must be double. One shall be handled to the concrete doctor that executes the test or surgery technique. The other shall regard anesthesiology insights, advantages and disadvantages or different alternatives for the needed anesthetic treatment, due to risks inevitably attached to the anesthesia itself.

Palabras clave: consentimiento, informado, anestesiología, lex artis.

Keywords: informed, consent, anesthesiology, lex artis.

Recepción original: 26/10/2015

Aceptación original: 04/11/2015

Sumario: I. Consentimiento informado como elemento integrante de la lex artis. I.1. Conceptualización y antecedentes. II. Presupuestos del consentimiento informado. II.1. El titular del derecho a la información. II.1.1. Breve alusión al caso de menor y del enfermo mental. II.2. El responsable de proporcionar la información al paciente. II.3. La forma de la información, del consentimiento y su valor ad probationem. II.4. El objeto del consentimiento y el contenido de la información. II.4.1. La información sobre los riesgos del acto anestésico. II.5. Momento en que debe prestarse el consentimiento informado por el paciente. II.5.1. Referencia a la legislación autonómica.

\section{CONSENTIMIENTO INFORMADO COMO ELEMENTO INTEGRANTE DE LA LEX ARTIS}

\section{I.1. Conceptualización y antecedentes}

Téngase presente que aunque la importancia de la información al paciente en la toma de decisiones y del respeto a su voluntad surgió por primera vez en la jurisprudencia norteamericana, en concreto, en el caso de Schloendorff, versus Society of New York Hospitals de 1914, donde se reconoció el derecho del paciente a la «autodeterminación» o a la autonomía en la decisión ${ }^{1}$ sentándose con ello el requisito del

\footnotetext{
${ }^{1}$ Sentencia del Juez CARDOZO en el caso de Schloendorff de 1914, contra la Society of New York Hospitals (1914) (VV. AA: Lexicón: Términos ambiguos y discutidos
} 
paciente al consentimiento, lo cierto es que será con posterioridad cuando se construya el vínculo entre la obligación de obtener el consentimiento y la obligación de suministrar al paciente la información.

En este sentido, el término "consentimiento informado» apareció por primera vez en una sentencia norteamericana de 1957, concretamente, en el caso Salgo v. Leland Standford, Jr. University Borrad of Trustees $^{2}$, aunque será con la sentencia del caso Canterbury versus Spencer, de 1972 cuando definitivamente se sienten las bases de la doctrina del consentimiento informado, al establecer el Tribunal que:

"Es el derecho de autodeterminación del paciente el que establece la carga del deber de revelación. Este derecho solo puede ejercerse de forma efectiva si el paciente posee una información suficiente que le capacite para elegir de forma inteligente».

A mayor abundamiento, conviene puntualizar que dos han sido las premisas básicas que han conformado la doctrina del consentimiento informado: de una parte, la obligación de proporcionar por el facultativo al paciente la información adecuada antes de proceder a realizarle cualquier intervención; de otra, la potestad que ostenta el paciente para rechazar una intervención y, por tanto, la consecuencia mediata de que surja la obligación de que se produzca un acto suyo de autorización previa a la misma.

sobre familia, vida y cuestiones éticas, Consejo Pontificio para la Familia, Madrid, 2006, 2. ${ }^{\text {a }}$ ed., pág. 118).

${ }^{2}$ En este caso, el paciente afectado de arteriosclerosis, se sometió a una aortografía diagnóstica, bajo anestesia y con el uso del contraste, presentando al día siguiente de su práctica, como complicación de la misma, una parálisis irreversible de los miembros inferiores de la que no había sido advertido. El tribunal estimó la demanda en base a esa omisión informativa del médico, destacando la relevancia de información previa al consentimiento, a fin de que el paciente pueda tomar una decisión autónoma. La doctrina emanada de aquella resolución completó la fijada en 1914 y referida al caso de Schloendorff, contra la Society of New York Hospitals, en la que la paciente dio su consentimiento para que el médico examinara, bajo anestesia, si el tumor fibroide que presentaba era benigno o maligno, pero no para su exégesis, a pesar de lo cual el cirujano lo extirpó, surgiendo en el post-operatorio una gangrena que hizo necesaria la amputación de varios dedos de la mano izquierda.

En esta sentencia, por primera vez, se fundó la condena en el reconocimiento expreso del consentimiento del paciente como un presupuesto esencial para el ejercicio de su derecho a la libre determinación, declarando el juez BENJAMÍN CARDOZO que «cada ser humano de edad adulta y sano juicio tiene derecho a determinar lo que debe hacerse con su propio cuerpo; un cirujano que realiza la intervención sin el consentimiento de su paciente comete una agresión de cuyas consecuencias es responsable» (TARODO SORIA, Salvador: «La doctrina del consentimiento informado en el ordenamiento jurídico norteamericano», en Derecho y Salud, Vol. 14, núm. 1, 2006, págs. 127 a 147). 
De modo que esta doctrina del consentimiento informado constituye el respeto a la autonomía del paciente como un requisito imprescindible de la relación sanitaria legítima.

En virtud de lo anterior se justifica la afirmación que sostiene que, el «consentimiento informado» se define como el acto mediante el cual el paciente, y después de que le hayan sido explicadas las principales características de una intervención, autoriza al facultativo a poner en práctica un tratamiento, mientras que el «derecho al consentimiento informado», se concibe como el derecho del paciente a ser informado y a dar o negar su autorización, antes de iniciar cualquier tratamiento que le afecte ${ }^{3}$.

Por otra parte, y respecto del mencionado Derecho de autodeterminación, conviene puntualizar que se encuentra basado en los principios de dignidad de la persona y de libre desarrollo de la personalidad regulados por el artículo $10^{4}$ de la Constitución Española y, asimismo, acogido por el Convenio para la Protección de los Derechos Humanos y la Dignidad del Ser Humano respecto de las Aplicaciones de la Biología y la Medicina, aprobado por la Asamblea Parlamentaria del Consejo de Europa en 1996 y abierto a la firma de los Estados miembros en Oviedo en 1997, entrando en vigor en España en el año 2000.

Este Convenio que dedica su Capítulo II al consentimiento del paciente, es desarrollado detalladamente en sus artículos $5^{5}$ a 9 , sentando como principio general que nadie puede ser forzado a someterse a una intervención médica sin su consentimiento.

Además también ha sido contemplado por la normativa internacional, así la Declaración sobre la promoción de los pacientes en Europa, promovida en 1994 por la Oficina Regional para la Europa de la

${ }^{3}$ Vid., en este sentido, MÉNDEZ BAIGES, Víctor y SILVEIRA GORSKI, Héctor Claudio: Bioética y derecho, Ed., UOC, Barcelona, 2007, pág. 77.

${ }_{4}$ «10.-1. La dignidad de la persona, los derechos inviolables que le son inherentes, el libre desarrollo de la personalidad, el respeto a la ley y a los derechos de los demás son fundamento del orden politico y de la paz social. -2. Las normas relativas a los derechos fundamentales y a las libertades que la Constitución reconoce se interpretarán de conformidad con la Declaración Universal de Derechos Humanos y los tratados y acuerdos internacionales sobre las mismas materias ratificados por España».

${ }^{5}$ En concreto y, por lo que aquí interesa, el Convenio de Oviedo o de Asturias en su artículo 5, prevé que: «Una intervención en el ámbito de la sanidad sólo podrá efectuarse después de que la persona afectada haya dado su libre e informado consentimiento. Dicha persona deberá recibir previamente una información adecuada acerca de la finalidad y la naturaleza de la intervención, así como sobre sus riesgos y consecuencias. En cualquier momento la persona afectada podrá retirar libremente su consentimiento» (BOE núm. 251, de 20 octubre de 1999, págs. 36825 a 36830). 
Organización Mundial de la Salud, y más recientemente, por la Carta de los Derechos Fundamentales de la Unión Europea, aprobada en Nizaen $2000^{6}$, que en su artículo $3^{7}$ se refiere a los derechos de los ciudadanos en relación con la medicina y la biología.

Por otra parte, el Manual de Ética de 1984 de la Asociación Médica Americana, establece que:

"El consentimiento informado consiste en la explicación, a un paciente atento y mentalmente competente, de la naturaleza de la enfermedad, así como del balance entre los efectos de la misma y los riesgos y beneficios de los procedimientos terapéuticos recomendados, para a continuación solicitarle su consentimiento para ser sometido a esos procedimientos. La presentación de la información al paciente ser comprensible y no sesgada; la colaboración del paciente debe ser conseguida sin coerción; el médico no debe sacar partido de su potencial dominancia psicológica sobre el paciente».

En virtud de lo anterior se justifica la afirmación que sostiene que, el precepto comprende tanto el deber del médico de facilitar una información completa y adecuada respecto del tratamiento prescrito previamente al paciente, como el deber de obtener el consentimiento de éste con anterioridad a iniciar el tratamiento, la intervención quirúrgica o las pruebas diagnósticas.

Sentadas las premisas anteriores, y desde el punto de vista estatal conviene precisar que, en España la primera referencia legal sobre el consentimiento del paciente, como derecho, se encuentra recogida en la Ley 14/1986, de 25 de abril, General de la Sanidad (en adelante LGS), que recogía en su artículo 10 los derechos de los pacientes y en su apartado sexto ${ }^{8}$ el derecho del paciente a decidir entre las diversas

${ }^{6}$ Diario Oficial de las Comunidades Europeas (2000/C 364/01).

${ }^{7}$ «-1. Toda persona tiene derecho a su integridad física y psíquica. -2. En el marco de la medicina y la biología se respetarán en particular: el consentimiento libre e informado de la persona de que se trate, de acuerdo con las modalidades establecidas en la ley; la prohibición de las prácticas eugenésicas, y en particular las que tienen por finalidad la selección de las personas; la prohibición de que el cuerpo humano o partes del mismo en cuanto tales se conviertan en objeto de lucro; la prohibición de la clonación reproductora de seres humanos".

${ }^{8}$ Decía el mencionado apartado: «Todos tienen los siguientes derechos con respecto a las distintas administraciones públicas sanitarias: -6. A la libre elección entre las opciones que le presente el responsable médico de su caso, siendo preciso el previo consentimiento escrito del usuario para la realización de cualquier intervención, excepto en los siguientes casos: a) Cuando la no intervención suponga un riesgo para la salud pública. b) Cuando no esté capacitado para tomar decisiones, en cuyo caso, el derecho corresponderá a sus familiares o personas a él allegadas. c) Cuando la urgencia no permita demoras por poderse ocasionar lesiones irreversibles o existir peligro de fallecimiento".

(C) UNED. Revista de Derecho UNED, núm. 17, 2015 
opciones. Precepto que contemplaba la necesidad de información previa para poder ejercer el derecho a decidir y elegir.

Téngase presente que el contenido del ya derogado artículo 10 LGS se ha realizado de forma parcial en algunas Comunidades Autónomas (en adelante CCAA) y de forma completa a nivel estatal. De forma tal que, ahora, el consentimiento informado se encuentra definido por la Ley 41/2002, de 14 de noviembre, básica reguladora de la autonomía del paciente y de derechos y obligaciones en materia de información y documentación clínica, en su artículo 3, como:

"La conformidad libre, voluntaria y consciente de un paciente, manifestada en el pleno uso de sus facultades después de recibir la información adecuada, para que tenga lugar una actuación que afecta a su salud».

Del contenido del texto del precepto se desprende que dicho consentimiento supone que el paciente por el hecho de serlo y acudir a la asistencia médica ni pierde su dignidad de persona humana ni los derechos que le son inherentes, entre los que se encuentra la libertad y, más concretamente, el derecho de autodeterminación, con relación a la salud. Por tanto, tendrá derecho a conocer el diagnóstico de su enfermedad, las consecuencias de ésta y los posibles tratamientos y sus efectos, para con posterioridad, decidir lo que estime más conveniente.

En este sentido, hay que aludir a la doctrina del Tribunal Supremo, debido a que cataloga el consentimiento informado como un derecho fundamental. Así, en la Sentencia del Tribunal Supremo, Sala 1. ${ }^{a}$, de lo Civil, de 12 de enero de 20019 (TOL4.964.609) -siendo ponente MARTÍNEZ-PEREDA RODRÍGUEZ-, se califica el consentimiento informado como un derecho fundamental en la siguiente forma:

«El consentimiento informado constituye un derecho humano fundamental, precisamente una de las últimas aportaciones realizadas en la teoría de los derechos humanos, consecuencia necesaria o explicación de los clásicos derechos a la vida, a la integridad física y a la libertad de conciencia. Derecho a la libertad personal, a decidir por sí mismo en lo

${ }^{9}$ En idéntico sentido, se ha pronunciado la STS, Sala $1 .{ }^{a}$, de lo Civil, de 11 de mayo de 2001, [TOL4.974.267] -siendo ponente MARTÍNEZ-CALCERRADA GÓMEZ-, al disponer que: "El consentimiento informado constituye un derecho humano fundamental, precisamente una de las últimas aportaciones realizada en la teoría de los derechos humanos, consecuencia necesaria o explicación de los clásicos derechos a la vida, a la integridad física y a la libertad de conciencia. Derecho a la libertad personal, a decidir por sí mismo en lo atinente a la propia persona y a la propia vida y consecuencia de la auto-disposición sobre el propio cuerpo». 
atinente a la propia persona y a la propia vida, y consecuencia de la autodisposición sobre el propio cuerpo» ${ }^{10}$.

De lo anterior se desprende, que para el TS el consentimiento informado no es únicamente un derecho subjetivo atribuido por Ley, sino que alcanza la categoría de Derecho Fundamental. De forma tal, que para este Alto Tribunal la información del médico al paciente para que éste pueda escoger en libertad dentro de las posibles opciones «no supone un mero formalismo, sino que encuentra su fundamento y apoyo en la misma constitución española, siendo las bases sobre las que descansa dicha protección, la dignidad de la persona y la libertad ${ }^{11}$.

También, el Tribunal Constitucional defiende que el consentimiento del paciente a cualquier intervención sobre su persona es algo inherente a su derecho fundamental a la integridad física. Así, en la Sentencia del Tribunal Constitucional, Sala 2. ${ }^{a}$, de 28 de marzo de 2011 (TOL2.084.764), -siendo ponente PÉREZ VERA- otorga el amparo por vulneración de los derechos a la integridad física y a la tutela judicial efectiva en un caso de reclamación de responsabilidad civil derivada de asistencia sanitaria, por la pérdida funcional de la mano derecha tras la realización de un cateterismo cardiaco sin el consentimiento del paciente.

De modo que tras rechazar la teoría de que el consentimiento tenga su encuadre en el artículo 17.1 CE, debido a que la libertad protegida por dicho precepto no cubre una libertad de autodeterminación individual, puesto que «la libertad personal protegida por ese artículo es la «libertad física»[...]» ${ }^{12}$, lo sitúa bajo la protección de la integridad

${ }^{10}$ El Magistrado, fundamenta su tesis apoyándose en los artículos 9.2, 10.1 y $1.1 \mathrm{CE}$ y en los Pactos Internacionales como la Declaración Universal de Derechos Humanos de 10 de diciembre de 1948, proclamada por la Asamblea General de las Naciones Unidas, principalmente en su Preámbulo y en los artículos 12, 18 a 20, 25, 28 y 29; el Convenio para la Protección de los Derechos Humanos y de las Libertades Fundamentales, de Roma de 4 de noviembre de 1950 en sus artículos 3 a 5 y 8 y 9 y, del Pacto Internacional de Derechos Civiles y Políticos de Nueva York, de 16 de diciembre de 1966, en sus artículos 1, 3, 5 y 8 a 10.

${ }^{11}$ Vid., así, GARCÍA GARNICA, María del Carmen: Nuevas perspectivas del tratamiento jurídico de la discapacidad y la dependencia, Ed. Dykinson, Madrid, 2014, pág. 120.

${ }_{12}$ Vid., en este sentido, entre otras, las STC, Pleno, de 16 de julio de 1987 [Vlex 126/1987] entiende el precepto como «un derecho mínimo y absoluto a la seguridad jurídica, y no exclusivamente como garantía frente a las interferencias arbitrarias en la libertad personal». Asimismo, la STC, Sala 2. ${ }^{\text {a }}$, de 18 de febrero de 1988 [Vlex 22/1988], sostiene que: "No es posible equiparar la privación de libertad a que se refiere el art. 17 CE en sus diversos apartados con la presencia física de una persona en las dependencias policiales para la práctica de una diligencia por el tiempo estrictamen-

(C) UNED. Revista de Derecho UNED, núm. 17, 2015 
física y moral del artículo $15^{13}$, señalando en su fundamento quinto, que:

"El consentimiento del paciente a cualquier intervención sobre su persona es algo inherente, entre otros, a su derecho fundamental a la integridad física, a la facultad de éste supone impedir toda intervención no consentida sobre el propio cuerpo, que no puede verse limitada de manera injustificada como consecuencia de una situación de enfermedad. Se trata de una facultad de autodeterminación que legitima al paciente, en uso de la autonomía de su voluntad, para decidir libremente sobre las medidas terapéuticas y tratamientos que puedan afectar a su integridad, escogiendo entre las distintas posibilidades, consintiendo su práctica o rechazándolas. Ésta es precisamente la manifestación más importante de los derechos fundamentales que pueden resultar afectados por una intervención médica: la de decidir libremente entre consentir el tratamiento o rehusarlo, aun cuando pudiera conducir a un resultado fatal. Ahora bien, para que esa facultad de consentir, de decidir sobre los actos médicos que afectan al sujeto pueda ejercerse con plena libertad, es imprescindible que el paciente cuente con la información médica adecuada sobre las medidas terapéuticas, pues solo si dispone de dicha información podrá prestar libremente su consentimiento, eligiendo entre las opciones que se le presente, o decidir, también con plena libertad, no autorizar los tratamientos o las intervenciones que se le propongan por los facultativos. De esta manera, el consentimiento y la información se manifiestan como dos derechos tan estrechamente imbricados que el ejercicio de uno depende de la previa correcta atención del otro, razón por la cual la privación de información no justificada equivale a la limitación o privación del propio derecho a decidir y consentir la actuación médica, afectando así al derecho a la integridad física del que ese consentimiento es manifestación».

En suma, el TC sostiene que aunque el artículo $15 \mathrm{CE}$ no contiene una referencia expresa al consentimiento informado, este instituto no queda al margen de la previsión constitucional de protección de la integridad física y moral, sino que:

"Los preceptos constitucionales relativos a los derechos fundamentales y libertades públicas pueden no agotar su contenido en el reconocimiento de éstos, sino que, va más allá de ello, pueden contener exigencias dirigidas al legislador en su labor de continua configuración del ordenamiento jurídico, ya sea en forma de principios rectores de contor-

te necesario para llevarla a efecto". También, la STC, Sala 2. ${ }^{a}$, de 8 de junio de 1988 [Vlex 112/1988] en relación al artículo 17. 1 CE prevé que: «el derecho fundamental consagrado en el art. 17. 1 CE que obliga a interpretar restrictivamente cualquier excepción a la regla general de libertad [...]» y, vid., STC, Sala 1. a , de 29 de marzo de 1990 [Vlex 61/1990]. En doctrina, vid., MARCOS DEL CANO, Ana María. Voluntades Anticipadas, Ed. Dykinson, Madrid, 2014, 1. ${ }^{\mathrm{a}}$ ed., pág. 154.

${ }^{13}$ En este sentido, vid., las aportaciones de BELLO JANEIRO, Domingo. Régimen Jurídico de la Responsabilidad Sanitaria, Reus, Zaragoza, 2013, 1. a ed., pág. 210. 
nos más amplios, ya sea en forma de bienes jurídicos constitucionales protegidos ${ }^{14}$.

En virtud de lo anterior se justifica la afirmación que sostiene la imprecisión que presenta la denominación, debido a la conveniencia de haber utilizado la calificación de "derecho de la personalidad», por ser indisponible ${ }^{15}$.

Así, ROMEO CASABONA puntualiza que «esta expresión en tanto no puede aceptarse que se trate propiamente de un derecho fundamental, si bien es innegable que los textos normativos nacionales e internacionales destacan esta facultad. La misma informa, sin duda, el ejercicio de derechos fundamentales como el derecho al libre desarrollo de la personalidad y el derecho a la libre determinación de la autonomía de la voluntad» ${ }^{16}$.

También RODRÍGUEZ LÓPEZ, precisa del concepto de consentimiento informado que «es la dignidad de la persona humana, desde la perspectiva del derecho a la autonomía individual como exponente del derecho a la libertad, el justificante último de la necesidad del consentimiento informado» ${ }^{17}$.

Por otra parte, conviene precisar que aunque casi todas las legislaciones autonómicas relativas a la salud se refieren de forma especial a la problemática que presenta el consentimiento informado ${ }^{18}$, lo

${ }^{14}$ En idéntico sentido, vid., STC, Pleno, 19 de diciembre de 1996 [Vlex 212/1996] -siendo ponente CRUZ VILLALÓN-, preciso que: «los preceptos constitucionales relativos a los derechos fundamentales y libertades públicas pueden no agotar su contenido en el reconocimiento de los mismos, sino que, más allá de ello, pueden contener exigencias dirigidas al legislador en su labor de continua configuración del ordenamiento jurídico, ya sea en forma de las llamadas garantías institucionales, ya sea en forma de principios rectores de contornos más amplios, ya sea, como en seguida veremos, en forma de bienes jurídicos constitucionalmente protegidos».

${ }^{15}$ Así, SANCHO GARGALLO, Ignacio. «Tratamiento legal y jurisprudencial del consentimiento informado», en Indret: Revista para el Análisis del Derecho, núm. 2, 2004, p. 5.

${ }^{16}$ La ética y el derecho ante la biomedicina del futuro, Universidad de Deusto, Bilbao, 2006, pág. 110.

${ }^{17}$ Responsabilidad médica y hospitalaria, Ed. Bosch, Barcelona, 1004, pág. 115.

${ }^{18}$ Entre otras, vid., la Ley 21/2000, de 29 de diciembre, sobre los derechos de información concerniente a la salud y la autonomía del paciente, y a la documentación clínica de Catalunya (art. 6.1); Ley 12/2001, de 21 de diciembre, de Ordenación Sanitaria de la Comunidad de Madrid (art. 27.1); Ley 6/2012, de 15 de abril, de Salud de Aragón (art. 12.1); Ley 2/2002, de 17 de abril, de Salud de la Rioja (art. 6); Ley de Cantabria 7/2002, de 10 de diciembre, de Ordenación Sanitaria de Cantabria (arts. 30); Ley 10/2014, 29 diciembre, de la Generalitat, de Salud de la Comunitat Valenciana (art. 43.1); Ley 5/2003 de 4 de abril, de salud de las Illes Balears (art. 12.1) y, Ley $8 / 2003$, de 8 de abril, sobre derechos y deberes de las personas en relación con la salud (arts. 5, 6, 18 y 33 a 35). 
cierto es que únicamente algunas de ellas contienen dentro de su articulado una definición del mismo.

En virtud de lo anterior, conviene destacar que la Ley 3/2001, de 28 de mayo, reguladora del consentimiento informado y de la historia clínica de los pacientes de Galicia, dispone en su artículo 3.1 (tras la modificación operada en éste por 3/2005, de 7 de marzo, de modificación de la Ley 3/2001, de 28 de mayo, reguladora del consentimiento informado y de la historia clínica de los pacientes), que:

"A los efectos de la presente Ley, se entiende por consentimiento informado el prestado libre y voluntariamente por el afectado para toda actuación en el ámbito de su salud y una vez que, recibida la información adecuada, hubiera valorado las opciones propias del caso» ${ }^{19}$.

Por su parte, la Ley 3/2005, de 8 de julio, de información sanitaria y autonomía del paciente de Extremadura, en su artículo 23.1 dispone que: "A los efectos de la presente Ley, se entiende por consentimiento informado la conformidad expresa del paciente, manifestada de forma voluntaria y libre, previa obtención de la información adecuada con tiempo suficiente, para la realización de cualquier actuación relativa a su salud».

Téngase presente que lo anterior debe ponerse en correlación con el artículo 5 del ya mencionado Convenio de Oviedo relativo a los Derechos Humanos y Biomedicina, conforme al cual:

${ }^{19}$ Se rectifica con ello la redacción originaria del precepto, conforme al cual se definía el consentimiento informado como la conformidad expresa del paciente, manifestada por escrito, previa obtención de la información adecuada, para la realización de un procedimiento diagnostico o terapéutico que afecte a su persona y que comporte riesgos importantes, notorios o considerables. En este sentido, DOMINGO LUELMO, Andrés (en «Régimen jurídico del consentimiento informado y la historia clínica de los pacientes en la Ley Gallega 3/2001, de 28 de mayo», en Revista Xurídica Galega, núm. 33, 2001, pág. 330) sostiene que «parecía que para el legislador gallego solo se precisara el consentimiento informado en estos supuestos y no en cualquier intervención en el ámbito de la salud, lo que entraba en contradicción con el espíritu de la propia Ley». Enfoque que se presenta en idénticos términos en el artículo 10. 4 del Código de Ética y Deontología Médica de la Organización Médica Colegial de 1999, debido a que, tras establecer la obligación de informar al paciente en todo caso, dispone que: "Cuando las medidas propuestas supongan para el paciente un riesgo significativo el médico le proporcionará información suficiente y ponderada a fin de obtener, preferentemente por escrito, el consentimiento específico imprescindible para practicarlas». Por el contrario, el Código Deontológico del Consejo de Médicos de Catalunya, se expresa en su artículo 13 con una mayor claridad al establecer que «el médico no podrá tratar a ningún paciente con la capacidad mental conservada sin su consentimiento". También, del mismo autor, vid., Derecho sanitario y responsabilidad médica: (comentarios a la Ley 41/2002, de 14 de noviembre, sobre derechos del paciente, información y documentación clínica), Ed. Lex Nova, Madrid, 2007, pág. 178. 
"Una intervención en el ámbito de la sanidad solo podrá efectuarse después de que la afectada haya dado su libre e inequívoco consentimiento. Dicha persona deberá recibir previamente una información adecuada acerca de la finalidad y naturales de la intervención, así como sobre sus riesgos y consecuencias».

Retomando nuevamente los requisitos exigidos por el artículo 3 de la Ley 41/2002, de 14 de noviembre, conviene precisar, que este consentimiento que deberá indudablemente ser «libre» y «voluntario». Además, únicamente podrá ser «consciente», evidenciándose el hecho de que determinadas personas -como se analizará en un epígrafe posterior-, no podrán consentir por sí mismas, sino que requerirán de la representación de otra persona.

En este sentido, y partiendo de la premisa, del amplio elenco jurisprudencial interpretativo que existe sobre la aplicación de los elementos que integran la configuración del consentimiento informado, debido a su tardía regulación, destaca el hecho de que uno de los aspectos fundamentales establecidos por el TS -en el que la doctrina es unánime-, se concrete en la integración del deber de información del facultativo al paciente, con la finalidad de obtener el correspondiente consentimiento previo, como un elemento más de la lex artis ad-hoc.

Desde el punto de vista de la mejor doctrina, esta teoría ha sido ampliamente desarrollada por GALÁN CORTÉS, al precisar que «el consentimiento informado es un presupuesto y elemento esencial de la lex artis, cuya omisión puede generar responsabilidad cuando se materializan los riesgos típicos de los que el paciente no ha sido informado". Además este autor añade que "forma parte de toda actuación asistencial y se encuentra incluido dentro de la obligación de medios asumida por el médico, por tanto, se constituye como una exigencia de la lex artis, para poder realizar la actividad médico-quirúrgica» ${ }^{20}$.

También, SOUTO PAZ, PORRAS Y MARTÍNEZ, precisan que «el consentimiento informado, se constituye como un presupuesto y elemento integrante de la lex artis, que se ha incorporado a nuestro derecho positivo en fechas recientes ${ }^{21}$.

${ }^{20}$ Responsabilidad Médica y consentimiento informado, Ed. Civitas, Madrid, 2001, pág. 23; ID: «Responsabilidad civil..., op. cit., págs. 1055 y ss.; ID: «Consentimiento informado: situación actual e incidencia en las especialidades médicas», en Actualidad del Derecho Sanitario, núm. 91, 2003, págs. 119 a 124.

${ }^{21}$ El consentimiento informado, Congregación de las Hermanas Hospitalarias del Sagrado Corazón de Jesús, 1999, pág. 16. 
Por su parte, LARIOS RISCO sostiene que «en relación al encuadramiento del deber de información y del consentimiento entre los elementos y requisitos de la responsabilidad civil, la doctrina de los tribunales revela una creciente importancia de ambos elementos de tal suerte que en algunos pronunciamientos se considera que el consentimiento es un elemento que forma parte de la lex artis, $y$, en concreto, de la obligación de medios, por lo que faltando la información se infringe la lex artis, $y$ es procedente la indemnización de daños» ${ }^{22}$.

De modo que nos encontramos ante un acto o proceso clínico más ${ }^{23}$ cuyo incumplimiento puede generar responsabilidad siendo, en la actualidad, una de las principales causas de condena en los supuestos de responsabilidad civil médica.

${ }^{22}$ Marco jurídico de las profesiones sanitarias, Ed. Lex Nova, Valladolid, 2007, p. 386.

${ }^{23}$ Desde el punto de vista jurisprudencial, vid., en este sentido, entre otras, las SSTS, Sala 3. ${ }^{\mathrm{a}}$, de lo Contencioso-Administrativo, Sección 6. ${ }^{\mathrm{a}}$, de 4 de abril de 2000 [Vlex 8065/1995] -siendo ponente XIOL RÍOS-; Sala 1. ${ }^{\mathrm{a}}$, de lo Civil, de 25 de abril de 1994 [Vlex 349/1994] -siendo ponente ALBACAR LÓPEZ-; Sala 1. ${ }^{\text {, }}$ de lo Civil, de 11 de febrero de 1997 [Vlex 83/1997] -siendo ponente ALMAGRO NOSETE-; Sala 1. ${ }^{\text {a }}$, de lo Civil, de 24 de mayo de 1999 [Vlex 445/1999] -siendo ponente GARCÍA VARELA-; Sala 1. ${ }^{\mathrm{a}}$, de lo Civil, 21 de diciembre de 2005 [Vlex 1002/2005] -siendo ponente SEIJAS QUINTANA-; Sala $1 .^{\mathrm{a}}$, de lo Civil, de 10 de mayo de 2006 [Vlex 488/2006] -siendo ponente SEIJAS QUINTANA-; Sala $1{ }^{\text {a }}$, de lo Civil, de 15 de noviembre de 2006 [RJ 2006/8059] -siendo ponente SEIJAS QUINTANA-; Sala 1. ${ }^{\text {a }}$, de lo Civil, de 21 de diciembre de 2006 [Vlex 1367/2006] -siendo ponente SEIJAS QUINTANA-; Sala 1. a , de lo Civil, de 10 de noviembre de 1997 [RJ 1997/7868] -siendo ponente GARCÍA VARELA-; Sala 1. ${ }^{\text {a }}$, de lo Civil, de 13 de abril de 1999 [RJ 1999/2583] -siendo ponente MARTÍNEZ-CALCERRADA GÓMEZ-; Sala 3. a , de lo ContenciosoAdministrativo, Sección 6. ${ }^{a}$, de 26 de marzo de 2004 [RJ 2004/3889] -siendo ponente SIERRA MÍNGUEZ; Sala 3. ${ }^{a}$, de lo Contencioso-Administrativo, Sección 6. ${ }^{\text {a }}$, de 20 de abril de 2005 [RJ 2005/4312] -siendo ponente PUENTE PRIETO-; Sala 3. ${ }^{\mathrm{a}}$, de lo Contencioso-Administrativo, Sección 6. ${ }^{\mathrm{a}}$, de 30 de marzo de 2004 [RJ 2004/2321] siendo ponente LECUMBERRI MARTÍ-; Sala $3{ }^{\mathrm{a}}{ }^{\text {, }}$, de lo Contencioso-Administrativo, Sección 6. ${ }^{\mathrm{a}}$, de 23 de febrero de 2007 [TOL1.042.443] -siendo ponente LECUMBERRI MARTÍ-; Sala 3. ${ }^{\mathrm{a}}$, Sección 6. ${ }^{\mathrm{a}}$, de lo Contencioso-Administrativo, de 23 de febrero de 2005 [TOL675.382] -siendo ponente LECUMBERRI MARTÍ-; Sala 3. ${ }^{\text {a }}$, de lo Contencioso-Administrativo, Sección $6 .^{\text {a }}$, de 14 de octubre de 2002 [Vlex 5294/1998] siendo ponente PÉREZ MORATE-; Sala 1. ${ }^{a}$, de lo Civil, de 20 de septiembre de 2005, en todas ellas se afirma que «el defecto de consentimiento informado se considera como un incumplimiento de la lex artis ad hoc y revela una manifestación de funcionamiento anormal del servicio sanitario que da lugar a la indemnización correspondiente cuando la actuación del servicio público sanitario derivan secuelas cuya posibilidad no fue informada por el paciente». También, la STS, Sala 3. ${ }^{\text {a }}$, de lo Contencioso-Administrativo, Sección 6. a , de 26 de mayo de 2015, [Vlex 2548/2013] -siendo ponente CUDERO BLAS-, afirmó que «la falta de consentimiento informado de la que fue objeto la paciente constituye una infracción de la lex artis y, por ende, es constitutiva de una infracción en el funcionamiento de la Administración que da derecho a ser indemnizado». 
Por lo que se refiere a esta materia, la Sentencia del Tribunal Supremo, Sala 1. ${ }^{a}$, de lo Civil, de 2 de octubre de 1997 (Vlex 830/1997) -siendo ponente SIERRA GIL DE LA CUESTA-, señala que:

"[...] un elemento esencial de la lex artis ad hoc es el de la obligación de informar al paciente», de lo que se deduce que su incumplimiento es constitutivo de una transgresión de esa lex artis ad hoc».

En idéntico sentido, se han pronunciado las Sentencias del Tribunal Supremo, Sala 1. a de lo Civil, de 29 de mayo (Vlex 511/1997)-siendo ponente VILLAGÓMEZ RODIL- y de 23 de julio de 2003 (RJ 2003/5462) -siendo ponente MARTÍNEZ-CALCERRADA Y GÓMEZ-, al declarar que:

"La obligación de informar al paciente es un elemento esencial de la lex artis ad hoc [...]. La información pretende iluminar al enfermo para que pueda escoger con libertad dentro de las opciones posibles, incluso la de no someterse a ningún tratamiento o intervención quirúrgica».

En suma, con la Ley 41/2002 24 , de 14 de noviembre, de una parte, se regula el derecho de información del paciente y la correlativa obligación del médico de informar, de otra, se destaca la condición de legislación básica que presenta el cuerpo legislativo -tal y como se desprende de forma expresa en su disposición adicional primera-, y cuya pretensión es garantizar a todos los ciudadanos unos derechos mínimos idénticos en esta materia, de forma tal que las distintas legislaciones autonómicas sí que podrán regular de forma expresa los derechos y deberes de los pacientes, pero no podrán indudablemente contradecir lo establecido por este marco legislativo y, finalmente, la técnica de la anestesiología requiere de su específico y propio consentimiento informado, consentimiento que deberá ser distinto del consentimiento exigido en la técnica quirúrgica per se, debido a que cada especialidad deberá ajustarse en todo momento a sus específicos y respectivos riesgos.

En este sentido, se ha pronunciado la ya mencionada Sentencia del Tribunal Supremo, Sala 1. ${ }^{a}$, de lo Civil, de lo Civil, de 25 de abril de 1994 (Vlex 349/1994) -siendo ponente ALBACAR LÓPEZ- en la cual se recoge, el derecho de información como uno de los componentes de la lex artis ad hoc, al establecer que:

"Informar al paciente o en su caso a los familiares del mismo, siempre, claro está, que esto resulte posible, del diagnóstico de la enfermedad

${ }^{24}$ En este sentido, la Ley 41/2002, de 14 de noviembre, en su artículo 2.6 prevé que: «Todo profesional que interviene en la actividad asistencial está obligado no sólo a la correcta prestación de sus técnicas, sino al cumplimiento de los deberes de información y de documentación clínica, y al respeto de las decisiones adoptadas libre y voluntariamente por el paciente». 
o lesión que padece, del pronóstico que de su tratamiento pueda normalmente esperarse, de los riesgos que del mismo, especialmente si éste es quirúrgico, puede derivarse y, finalmente, y en el caso de que los medios de que se disponga en el lugar donde se aplica el tratamiento puedan resultar insuficientes, debe hacerse constar tal circunstancia, de manera que si resultase posible, opte el paciente o sus familiares por el tratamiento del mismo en otro centro médico más adecuado. En resumen, el consentimiento prestado por el enfermo o sus parientes ha de ser informado. Tal información comprenderá para no incurrir en responsabilidad, el diagnóstico de la enfermedad o lesión que se padece, el pronóstico que de su tratamiento puede esperarse y los riesgos del mismo [...]».

Por otra parte, y sin ánimo de reiteración, en el ámbito de la anestesiología, conforme a los riesgos que comporta el acto anestésico, entendemos que será necesario obtener el consentimiento para el acto anestésico concreto -ya sea anestesia general o cualquier de cualquier otro tipo-, con independencia de la autorización conferida por el paciente para el acto quirúrgico al que vaya a ser sometido. Así como la necesidad de obtener la autorización previa del paciente o de su representante legal -para el caso de menor- resulta aquí de carácter ineludible.

A lo anterior no han faltado voces discrepantes que propugnan que «dado que el paciente sabe que actualmente cualquier intervención operatoria se efectúa bajo anestesia local o general, cabe suponer la conformidad del paciente a ser operado incluye el acuerdo a ser anestesiado $»^{25}$.

A mayor abundamiento, el consentimiento del paciente entendemos que deberá ser prestado antes de la administración de la preanestesia, con la finalidad de asegurar la plena eficacia del acto, siendo este consentimiento sumamente necesario en determinadas circunstancias, como sería el caso, por ejemplo, de pacientes con el estómago lleno y en los que se requiere realizar una intervención quirúrgica de urgencia bajo anestesia general, puesto que frente a los riesgos adicionales que ello comporta (como el de aspiración), es prudente que el paciente los conozca y acepte «como parte del consentimiento que otorga ${ }^{26}$.

${ }^{25}$ Así, FREY, Hügin, BENZER y MAYRHOFER, op. cit., pág. 1056.

${ }^{26}$ En este sentido, ORKIN y COOPERMAN precisan que: «El médico tiene que enfrentarse en ocasiones con un paciente que exige de un tratamiento inmediato que representa ciertos riesgos, pero que es preciso aplicar si se desea salvar su vida. En tal caso, debe advertir al paciente utilizando sus mejores argumentos, en un intento de obtener su consentimiento para aplicar de inmediato el tratamiento necesario» (op. cit., pág. 8). 
Lo anterior encuentra su justificación en que su omisión puede originar una responsabilidad en el médico-anestesista, debido a que una persona adulta mentalmente competente tiene derecho a decidir libremente que hacer con su cuerpo, y cualquier intervención sin su consentimiento constituye una vulneración a su derecho de autodeterminación, pero si el médico-anestesista facilita agentes anestésicos sin el debido consentimiento informado por escrito del paciente, indudablemente será responsable de los daños que puedan originarse en el paciente.

Así, y en relación a la responsabilidad civil que ostentan estos especialistas, en la ya mencionada la Sentencia del Tribunal Supremo, Sala 1. ${ }^{a}$, de lo Civil, de 12 de diciembre de 1998 (TOL5.119.629) -siendo ponente VILLAGÓMEZ RODIL- se precisa que:

"La responsabilidad civil de los anestesistas se exige cuando éstos no son rigurosos en la observancia y aplicación de las reglas y técnicas de esta especialidad médica, cuya funcionalidad no es la directa curación del enfermo, sino la de facilitar medios y proporcionar estados insensibles al dolor para propiciar la realización de actividades de diagnóstico, quirúrgicas y terapéuticas, lo que necesariamente impone la máxima atención y concentración en la aplicación del acto anestésico de los estándares que tienen como objetivo su seguridad y éxito, y entre éstos resulta imprescindible en todo momento la oxigenación, ventilación y circulación del paciente» ${ }^{27}$.

Por su parte, y en relación al consentimiento al acto anestésico la Sentencia del Tribunal Superior de Justicia de Galicia, Sección 3. ${ }^{a}$, Sala de lo Contencioso-Administrativo, de 25 de mayo de 2011 (TOL2.442.645) -siendo ponente DE LOYOLA ARANGUREN PÉREZ-, estableció que:

"El consentimiento escrito del paciente será necesario para cada una de las actuaciones especificadas en el punto 3 de este artículo 8 de la Ley 41/2002, de 14 de noviembre, dejando a salvo la posibilidad de incorporar anejos y otros datos de carácter general, y tendrá información suficiente sobre el procedimiento de aplicación y sobre sus riesgos».

${ }^{27}$ En este sentido, la STS, Sala 1. ${ }^{\text {a }}$, de lo Civil, de 13 de abril de 1999, señala que «la responsabilitat civil dels anestesistes s'exigeix quan aquests no són rigorosos en l'observança i aplicació de les regles i tècniques de la seva especialitat mèdica, la funcionalitat de la qual no és la directe curació del malalt sinó la de facilitar mitjans i proporcionar estats insensibles al dolor per propiciar la realització d'activitats de diagnòstic, quirúrgiques i terapèutiques. La funció, obligacions $i$ per tant la responsabilitat de l'anestesista és independent de què, en atenció al tipus de intervenció quirúrgica, el metge hagi assumit, d'acord amb la doctrina jurisprudencial abans examinada, una obligació de resultat o simplement d'activitat». 
Por ello, entendemos necesario obtener el consentimiento para la aplicación del acto anestésico, con independencia de la autorización conferida para al acto quirúrgico propiamente dicho.

\section{PRESUPUESTOS DEL CONSENTIMIENTO INFORMADO}

De lo visto hasta ahora, se desprende que para la emisión del consentimiento informado es preciso el análisis de las personas que intervienen el proceso, el contenido del mismo, así como el momento en el que se debe facilitar la información para que el paciente tome una decisión de forma libre y consciente.

\section{II.1. El titular del derecho a la información}

Como ya se ha anunciado, el «consentimiento informado» se encuentra basado fundamentalmente en la inferencia de que el paciente es el único que tiene derecho a determinar lo que quiere hacer o no con su cuerpo y, por tanto, la autodeterminación forma la base jurídica de la doctrina del consentimiento informado.

En este sentido, la doctrina es unánime en precisar que de conformidad con la naturaleza personalísima que presenta la figura, es evidente que el destinatario de la información será el paciente, debido a que éste es quien debe consentir la intervención médica, siempre que su capacidad natural de juicio y discernimiento se lo permita y, no nos encontremos ante supuestos de urgencia o riesgo para su salud, es decir, que si el paciente se presume capaz, en uso de su autonomía de la voluntad prestará directamente su consentimiento ${ }^{28}$.

En este sentido, la Sentencia del Tribunal Supremo, Sala 1. ${ }^{a}$, de lo Civil, 24 de mayo de 1995 (Vlex Núm. 490)-siendo ponente BARCALA TRILLO-FIGUEROA-, ha declarado que:

«El consentimiento es de índole personal y no puede ser suplido por el prestado por un familiar íntimo, ni siquiera por el cónyuge del interesado, a no ser la concurrencia de las repetidas circunstancias de (urgencia o incapacidad)».

Sentada la premisa anterior, conviene aludir al artículo 2.3 contenido en la Ley 41/2002, de 14 de noviembre, que establece como prin-

${ }^{28}$ Así, GALÁN CORTÉS. Responsabilidad civil..., op. cit., pág. 351; SÁNCHEZ GONZÁLEZ, María Paz La impropiamente llamada objeción de conciencia a los tratamientos médicos, Ed. Tirant lo Blanch, Valencia, 2002, pág. 236. 
cipio básico, que: «El paciente o usuario tiene derecho a decidir libremente, después de recibir la información adecuada, entre las opciones clinicas disponibles».

Por su parte, el artículo 5 de este cuerpo normativo, relativo al titular del derecho a la información, prevé que:

«1. El titular del derecho a la información es el paciente. También serán informadas las personas vinculadas a él, por razones familiares o de hecho, en la medida que el paciente lo permita de manera expresa o tácita».

A mayor abundamiento, y de conformidad con el articulado de esta ley, conviene precisar que esta información también le será facilitada al interesado, incluso en caso de incapacidad, de forma adecuada a sus posibilidades de comprensión, supuesto en el que deberá cumplirse con el deber de informar a su representante legal (art. 5.2). Además, si el paciente, a criterio del facultativo que le asiste, carece de la capacidad para entender la causa de su estado, la información deberá ser facilitada a las personas vinculadas con él por razones familiares o de hecho (art. 5.3) y, finalmente, el paciente deberá participar en la medida en que sea posible, en la toma de decisiones a lo largo del proceso sanitario (art. 9.5).

Sin embargo, este derecho que ostentan los pacientes a la información podrá verse limitado en su propio beneficio en los supuestos en que por razones objetivas el conocimiento de su propia situación pueda perjudicar su salud de forma grave, supuestos en los que el facultativo deberá dejar constancia razonada de las circunstancias en la historia clínica y comunicar su decisión a las personas vinculadas a él por razones familiares o de hecho (art. 5.4).

A lo anterior, conviene precisar que dicha comunicación no procederá en caso de que el propio paciente hubiera prohibido la difusión de tal información a dichas personas. Limitación recogida por la Declaración para la Promoción de los Derechos de los Pacientes en Europa, en los términos siguientes:

"La información puede ocultarse a los pacientes excepcionalmente cuando exista una razón suficiente para creer que esta información, en vez de efectos positivos, pudiera causarle graves daños» ${ }^{29}$.

GALÁN CORTÉS, establece que «dicha excepción a la información del paciente, derivada de un estado de necesidad terapéutica, debe inter-

${ }^{29}$ Consulta Europea sobre los derechos de los pacientes (Ámsterdam, 28-30 de marzo de 1994), pág. 8. 
pretarse de forma restrictiva, integrando tal concepto jurídico indeterminado en atención a las circunstancias concurrentes en cada caso ${ }^{30}$.

En este punto conviene matizar que, no debe confundirse este estado de necesidad terapéutica con la situación de un paciente afectado de un mal pronóstico, debido por ejemplo a que el paciente se encuentre en estado terminal, ya que en este caso se presupone que tiene derecho a conocer la verdad de su situación, sin perjuicio de la conveniencia de analizar cada caso concreto. En estos supuestos en los que el facultativo deberá actuar con la máxima cautela posible, se prevé la admisibilidad de facilitar una información de forma gradual, aconsejado por las circunstancias del caso concreto.

Ahora bien, para aquellos casos en los que sea el propio paciente el que renuncie expresamente a recibir tal información, deberá respetarse su voluntad, aunque indudablemente será necesaria la obtención de su previo consentimiento para la intervención (art. 9.1).

No obstante lo anterior, este derecho a no ser informado encuentra su limitación en el propio interés de la salud del paciente, de terceros, de la colectividad o por las exigencias terapéuticas del caso.

En este sentido, nuestro legislador ha previsto, las situaciones de conflicto entre el derecho a no saber y el interés de la salud del propio paciente o tercero. De forma tal, que en determinados supuestos podría ser vital para el paciente conocer ciertos datos sobre su estado de salud, aun cuando haya manifestado tal derecho a no ser informado, este sería el caso, por ejemplo, de una predisposición a padecer cierto proceso patológico, sin cuyo conocimiento no podría prevenirse o evitarse su aparición -supuesto que se trataría de una verdadera exigencia terapéutica-.

Asimismo, conviene puntualizar que este derecho a no ser informado que ya se encontraba establecido de forma expresa en el artículo 5.1 del Convenio de Oviedo, ha sido tradicionalmente admitido por la doctrina como un supuesto de excepción al deber de información del facultativo.

También la Ley 3/2005, de 23 de mayo, por la que se regula el ejercicio del derecho a formular instrucciones previas en el ámbito sanitario y se crea el registro correspondiente de la Comunidad de Madrid, en relación al ejercicio de este derecho a no ser informado para el caso de pacientes en estado terminal o pronóstico fatal, dispone en su artículo 6.4 que: «En el documento de instrucciones previas los pa-

\footnotetext{
${ }^{30}$ Responsabilidad civil..., op. cit., pág. 353.
} 
cientes podrán manifestar anticipadamente su voluntad de no ser informados en los supuestos de diagnóstico fatal. En este caso, el declarante podrá designar una o varias personas a las que el médico deba informar».

En suma, este derecho a no ser informado debe ser respetado y únicamente cederá en caso de salvaguarda de otros derechos a los que el legislador confiera una mayor relevancia ${ }^{31}$.

Asimismo, la Ley 41/2002, de 14 de noviembre, prevé en su artículo $9.2^{32}$ los supuestos en los que no se requiere del consentimiento informado previo para realizar las actuaciones médicas pertinentes en favor de la salud del paciente, al establecer que: "Los facultativos podrán llevar a cabo las intervenciones clínicas indispensables en favor de la salud del paciente, sin necesidad de contar con su consentimiento, en los siguientes casos:

a) Cuando existe riesgo para la salud pública a causa de razones sanitarias establecidas por la Ley. En todo caso, una vez adoptadas las medidas pertinentes, de conformidad con lo establecido en la Ley Orgánica 3/1986, se comunicarán a la autoridad judicial en el plazo máximo de 24 horas siempre que dispongan el internamiento obligatorio de personas.

b) Cuando existe riesgo inmediato grave para la integridad física o psíquica del enfermo y no es posible conseguir su autorización, consultando, cuando las circunstancias lo permitan, a sus familiares o a las personas vinculadas de hecho a él».

Por tanto, y como GALÁN CORTÉS acertadamente sostiene «únicamente en situaciones de auténtica e inmediata urgencia, en las que no sea posible obtener el consentimiento del interesado, podrá prescindirse del mismo en su único beneficio» ${ }^{33}$.

${ }^{31}$ Vid., SÁNCHEZ CARO, Javier. «Consentimiento informado y salud», en GUERRERO ZAPLANA (dir.), Salud pública y Derecho administrativo, Cuadernos de derecho judicial V/2003, Consejo del Poder Judicial, Madrid, 2004, págs. 181 y 182.

${ }_{32}$ Este precepto encuentra su precedente inmediato en el derogado artículo 10.6. c) de la LGS a cuyo tenor, «no se precisa el consentimiento del usuario cuando la urgencia no permita demoras por poderse ocasionar lesiones irreversibles o existir peligro de fallecimiento» y, también en el artículo 8 del Convenio de Oviedo, conforme al cual: «Cuando, debido a una situación de urgencia, no pueda obtenerse el consentimiento adecuado, podrá procederse inmediatamente a cualquier intervención indispensable desde el punto de vista médico en favor de la salud de la persona afectada».

33 "Servicios de Urgencias y consentimiento informado», en Diario Médico, Sección de Normativa, 2005, pág. 12. 
Este supuesto de urgencia podría tener lugar durante el curso de una intervención quirúrgica programada, con motivo de complicaciones surgidas o hallazgos encontrados durante su realización, de forma tal, que resultase imprescindible la ampliación de la cirugía y, en consecuencia, de la anestesia prevista inicialmente, y que tan solo con grave peligro para la salud del paciente podría posponerse, justificaría el proceder de los médicos intervinientes en el acto aun sin contar con la debida autorización otorgada por el paciente.

\section{II.1.1. Breve alusión al caso de menor y del enfermo mental}

Respecto al caso del menor, la Ley 41/2002, de 14 de noviembre, prevé en su artículo $9.3^{34}$.c) que en los supuestos en que éstos no sean capaces intelectual ni emocionalmente de comprender el alcance de la actuación o intervención médica, el consentimiento deberá ser prestado por el representante legal del menor, después de haber escuchado su opinión (art. 9 de la Ley Orgánica 1/1996, de 15 de enero, de Protección Jurídica del Menor ${ }^{35}$. Y añade, en su apartado 4 que "cuando se trate de menores emancipados o mayores de 16 años [...], no cabe prestar el consentimiento por representación. No obstante, cuando se trate de una actuación de grave riesgo para la vida o salud del menor, según el criterio del facultativo, el consentimiento lo prestará el representante legal del menor, una vez oída y tenida en cuenta la opinión del mismo ${ }^{36}$.

En síntesis, esta condición última únicamente será de aplicación en supuestos de especial gravedad -es decir, de aplicación restrictivay, por tanto, en los que la vida e integridad del menor corra un serio y grave peligro, ya que, de contrario, podría originarse una contradicción con el estado y circunstancias que deben darse en un menor maduro, debido a que si éste reúne condiciones de madurez suficiente, lógico es que se respete su libre y autónomo derecho de decisión.

Respecto al caso del enfermo mental, conviene puntualizar que también participará en la toma de decisiones en el transcurso del proceso sanitario [art. 9.7 ${ }^{37}$. En idéntico sentido, el artículo 9.5 del mis-

${ }^{34}$ Modificado por la Ley 26/2015, de 28 de julio, de modificación del sistema de protección a la infancia y a la adolescencia.

${ }^{35}$ Vid., RUIZ JIMENEZ, Juana. "La capacidad del menor», en VVAA, Protección

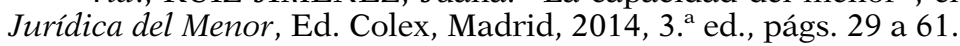

${ }^{36}$ Preceptos redactados por la Disposición final segunda de Ley 26/2015, de 28 de julio, de modificación del sistema de protección a la infancia y a la adolescencia.

${ }_{37}$ Apartado añadido por Ley 26/2015, de 28 de julio, de modificación del sistema de protección a la infancia y a la adolescencia. 
mo cuerpo legal, dispone que: «El paciente será informado, incluso en caso de incapacidad, de modo adecuado a sus posibilidades de comprensión, cumpliendo con el deber de informar también a su representante legal».

También, en relación a los pacientes adultos con disfunción mental, se ha pronunciado el Convenio de Oviedo en su artículo 6. 3, al prever que: «La persona afectada deberá intervenir, en la medida de lo posible, en el procedimiento de autorización».

Apoyándose en lo anterior, GALÁN CORTÉS, pone de manifiesto que «en el caso de enfermos mentales, la incidencia de dichos preceptos, es manifiesta ${ }^{38}$.

En definitiva, partiendo de la premisa de que no todo enfermo mental es un enfermo incapaz -aunque en algunas fases podría serlo-, se debe respetar el reducto de autonomía de que disponga, es decir, la capacidad de autogestión que ostente, y, en consecuencia, como la doctrina aboga resulta necesario respetarse su autonomía -si dispone de ella-, debiendo únicamente operar la representación de forma subsidiaria ${ }^{39}$.

\section{II.2. El responsable de proporcionar la información al paciente}

Respecto a la persona que debe facilitar la información al paciente, resulta obvio que esta información deberá ser suministrada al enfermo por el profesional sanitario que vaya a realizar la técnica diagnóstica o terapéutica concreta, al ser éste quien se encuentra en mejores condiciones para hacerlo y quien dispone del caudal informativo más completo y adecuado sobre tal proceder, sin perjuicio de que todo facultativo interviniente en el tratamiento del paciente le informe, dentro de su campo de actuación y posibilidades ${ }^{40}$.

${ }^{38}$ Responsabilidad civil..., op. cit., pág. 369 y, para una mayor argumentación sobre el consentimiento informado en estos casos, vid., del mismo autor: Responsabilidad Médica..., op. cit., págs. 93 a 104.

${ }^{39}$ Así, GRACIA GUILLÉN, Diego Miguel. "Evolución histórica y situación legal», Ponencia presentada en las II Jornadas jurídico-sanitarias de Navarra. El menor y su protección en el ámbito socio-sanitario, Pamplona, 2004.

${ }_{40}$ A este respecto, vid., las amplias aportaciones que en la materia ha realizado GALÁN CORTÉS. Responsabilidad civil..., op. cit., pág. 375. 
GALÁN CORTÉS y GALÁN GUTIÉRREZ precisan que «también podrá serle facilitada por otro médico del mismo servicio sanitario que vaya a realizar la intervención ${ }^{41}$.

En este sentido, la Sentencia del Tribunal Superior de Justicia de Catalunya, Sección 4. ${ }^{a}$, Sala de lo Contencioso Administrativo, de 31 de marzo de 2005 (núm. 270/2005) -siendo ponente GIMÉNEZ CABEZÓN-, con ocasión de una demanda interpuesta por una esterilización fallida, declaró sobre este aspecto que:

«no es un motivo para invalidar el consentimiento informado dado por el paciente, ni constituye un requisito sine qua non para anular su autorización, el hecho de que la información no sea facilitada por el propio médico que practique la operación, pues es válida y suficiente la realizada por otro facultativo en el ámbito del servicio sanitario correspondiente».

Sin embargo, la Ley 41/2002, de 14 de noviembre, en su artículo 4.3 precisa a este respecto, que: «El médico responsable del paciente le garantiza el cumplimiento de su derecho a la información. Los profesionales que le atiendan durante el proceso asistencial o le apliquen una técnica o un procedimiento concreto también serán responsables de informarle».

Punto en el que la doctrina mayoritaria ${ }^{42}$ ha sido unánime en puntualizar que resultan excesivas las obligaciones que recaen sobre el «médico responsable», teniendo presente que éste es quien tiene a su cargo coordinar la información y la asistencia sanitaria del paciente o usuario, con el carácter de interlocutor principal del mismo en todo lo concerniente a su atención e información durante el proceso asistencial [art. 3] ${ }^{43}$, y que por tanto, no será, en muchas ocasiones, el médico que le tratará en ciertas fases o momentos de su proceso.

En este sentido, GALÁN CORTÉS y GALÁN GUTIÉRREZ, precisan que «el médico responsable no puede garantizar el cumplimiento por parte del resto de médicos intervinientes que también deben infor-

41 "Consentimiento informado en anestesiología: la antelación suficiente como requisito de validez», en Revista Española en Anestesiología y reanimación, núm. 61 (2), 2014, pág. 96.

${ }^{42}$ GALÁN CORTÉS y GALÁN GUTIÉRREZ, op. cit., pág. 97.

${ }^{43}$ Reza el precepto en el sentido siguiente: «Médico responsable: el profesional que tiene a su cargo coordinar la información y la asistencia sanitaria del paciente o del usuario, con el carácter de interlocutor principal del mismo en todo lo referente a su atención e información durante el proceso asistencial, sin perjuicio de las obligaciones de otros profesionales que participan en las actuaciones asistenciales». 
mar respecto de su actuación sobre el paciente, ya que dicha responsabilidad resulta excesiva ${ }^{44}$.

También DE ÁNGEL YÁGÜEZ sostiene que la inclusión en la ley de esta figura del médico responsable ha sido desafortunada, ya que «desde este prisma ese médico responsable será el sujeto destinado a responder ante el juez por un defecto de forma en la información ${ }^{45}$.

De lo anterior, se desprende que el «médico responsable» deberá propiciar y fomentar tal información, pero no podrá garantizarla, siendo los especialistas de cada actuación concreta quienes sí deberán garantizar que ésta sea proporcionada al paciente en los términos precisos.

En idéntico sentido se ha pronunciado la jurisprudencia, en el entendido de que la finalidad es que el paciente obtenga un conocimiento previo, adecuado y razonable que deberá provenir del médico especialista del tratamiento concreto.

${ }^{44}$ Op. cit., pág. 376.

45 "Historia y documentación clínica», en X Congreso Nacional de Derecho Sanitario, Madrid, 2003 y, vid., en idéntico sentido las aportaciones de LIZZARAGA BONELLI, Emilio. «La información y la obtención del consentimiento en la nueva Ley 41/2002, básica, reguladora de la autonomía del paciente y de derechos y obligaciones en materia de información y documentación clínica», en LIZARRAGA BONELLI y GONZÁLEZ SALINAS (coodr.), Autonomía del paciente, información e historia clinica: (estudios sobre la Ley 41/2002, de 14 de noviembre), Ed. Civitas, Madrid, 2004, pág. 265. Desde el punto de vista de las legislaciones autonómicas, conviene precisar que dicho error ha sido enmendado por la Ley 8/2003, de 8 de abril, sobre derechos y deberes de las personas en relación con la salud, de la Comunidad Autónoma de Castilla y León, por cuanto establece en su artículo 21. 1 la figura del «médico responsable» y también la del «enfermero responsable», de forma que el primero únicamente actúa como interlocutor principal con el equipo asistencial pero no se le hace garante absoluto de toda la información. Reza el precepto en los siguientes términos: «En todos los centros, servicios o establecimientos debe asignarse a los pacientes un médico, que será su interlocutor principal con el equipo asistencial, y, en su caso, un enfermero responsable del seguimiento de su plan de cuidados. Su identificación debe darse a conocer a los destinatarios de la información asistencial». También, desde este punto de vista, la Guía de consentimiento informado elaborada por la Junta de Castilla y León de 2006: «El profesional que atienda al paciente o le aplique la técnica o procedimiento concreto deberá ser la persona encargada de informarle [...]. El profesional sanitario que vaya a llevar a cabo el procedimiento concreto, una vez que ha proporcionado la información al paciente o a quien deba sustituir su decisión, recabará su consentimiento [...]. Cuando el profesional que indica el procedimiento y el profesional que lo va a realizar no son la misma persona, el primero únicamente tiene la obligación de informar al paciente sobre las circunstancias de la indicación y sobre los aspectos básicos del procedimiento, siendo el profesional que lo va a realizar el responsable de asegurar que el paciente recibe la información necesaria y que presta su consentimiento» (pp. 14 y 15). 
En particular, la Sentencia del Tribunal Supremo, Sala 1. ${ }^{a}$, de lo Civil, de 26 de septiembre de 2000 -siendo ponente VILLAGÓMEZ RODIL-, declaró que:

«El deber de informar al paciente es de cargo directo y personal del facultativo que va a realizar la intervención, pues debe de conocer la transcendencia y alcance de la misma, detallando las técnicas disponibles».

También la Sentencia del Tribunal Supremo, Sala 1. ${ }^{a}$, de lo Civil, de 16 de octubre de 1998 (Vlex 956/1998) -siendo ponente BARCALA TRILLO-FIGUEROA-, en un supuesto en el que habían intervenido varios médicos y dos centros hospitalarios, declaró que:

"La obligación de informar correspondía a los profesionales que practicaron la prueba médica».

Por lo que aquí interesa, conviene precisar que en el caso de la anestesiología y, en concreto, en el supuesto de médicos-anestesistas de un servicio hospitalario, somos partidarios al igual que GALÁN CORTÉS y GALÁN GUTIÉRREZ, que cualquier facultativo del servicio podrá facilitar la información al paciente, dejando constancia en la historia clínica de éste, sin la necesidad de que la información sea suministrada directamente por el anestesista concreto que aplicará la anestesia $^{46}$.

En este sentido, la Sentencia del Tribunal Supremo, Sala 1. ${ }^{a}$, de lo Civil, de 20 de enero de 2011 (RJ 2011/299) -siendo ponente SEIJAS QUINTANA- desestimó la alegación de la demandante-recurrente en casación, relativa a que el anestesista no informó del plan anestésico a seguir y que no se interesó el consentimiento a la paciente, remitiéndose al consentimiento genérico firmado al cirujano. El alto Tribunal, fundamentó su fallo en una información por escrito y suficiente, incluso del anestesista, así como de intervenciones similares anteriores de ésta paciente y en el mismo centro.

En suma, el médico-anestesista deberá garantizar la información y no el médico responsable del paciente, que puede ser, por ejemplo, un cirujano y, por tanto, desconocedor de los pormenores y demás riesgos específicos de la técnica del acto anestésico a utilizar.

${ }^{46}$ Op. cit., pág. 97. 


\section{II.3. La Forma de la Información, del Consentimiento y su Valor ad probationem}

Respecto de la forma en que debe proporcionarse la información al paciente por el médico-anestesista y a la prestación del consentimiento a la intervención por el paciente se plantean las cuestiones de si debe entregarse y/o realizarse de forma verbal o por escrito.

En este sentido, la ya mencionada Ley 41/2002, de 14 de noviembre, refiriéndose a cualquier intervención en el ámbito de la salud prevé que, como norma general, la información se proporcione verbalmente ${ }^{47}$, dejando constancia en la historia clínica del paciente ${ }^{48}$ (art. $\left.4.1^{49}\right)$. Asimismo, en relación a la prestación del consentimiento contempla la misma forma verbal, pero con la salvedad de determinados supuestos regulados de forma expresa por este cuerpo legal (art. 8.2). Además, este cuerpo legislativo exige que quede constancia del consentimiento informado en la historia clínica, cuando se trate únicamente de procesos de hospitalización (art. 15.2.i).

De lo anterior se desprende que los preceptos referidos a la forma de información y del consentimiento informado, se encuentran dispersos en el articulado de este cuerpo legal, trasladando en la mayoría de los supuestos, la tendencia jurisprudencial anterior a su promulgación.

En la actualidad, la nueva redacción ha solventado acertadamente los problemas de interpretación suscitados por los derogados artículos 10.5 y 10.6 LGS, que exigían, de una parte, el derecho de todo paciente a que se le diera información verbal y escrita sobre su proceso y, de otra, el consentimiento escrito para la realización de cualquier intervención, debido a que, tras la modificación legislativa, tanto la información como el consentimiento se realizarán verbalmente -dejando constancia el facultativo de ello en la historia clínica del pacien-

${ }^{47}$ Vid., CANTERO MARTÍNEZ Josefa. La autonomía del paciente: del consentimiento informado al testamento vital, Ed. Bomarzo, Albacete, 2005, págs. 29 y ss.

${ }^{48}$ En este sentido, la STS, Sala 1. a, de lo Civil, de 29 de mayo de 2003 (Vlex 511/1997) -siendo ponente VILLAGÓMEZ RODIL- señala que «aunque se permita su práctica en forma verbal, al menos debe quedar constancia de la misma en la historia clinica del paciente y documentación hospitalaria que le afecte, como exige la Ley de 14 de noviembre de 2002».

${ }^{49}$ Establece el precepto: «[...] La información, que como regla general se proporcionará verbalmente dejando constancia en la historia clínica, comprende, como mínimo, la finalidad y la naturaleza de cada intervención, sus riesgos y sus consecuencias. -2. La información clínica forma parte de todas las actuaciones asistenciales, será verdadera, se comunicará al paciente de forma comprensible y adecuada a sus necesidades [...]».

(C) UNED. Revista de Derecho UNED, núm. 17, 2015 
te-, con la salvedad de las excepciones previstas por el artículo 8. 2 de la Ley 41/2002, de 14 de noviembre.

Por otra parte, en aquellos supuestos en que no se hubiese incorporado por escrito la información a la historia clínica, la jurisprudencia viene admitiendo para considerar acreditada la información y, con la finalidad, de no excluir de forma automática la validez del consentimiento, otros medios de prueba.

En este sentido, se ha pronunciado la Sentencia del Tribunal Supremo, Sala 1. ${ }^{a}$, de lo Civil, de 27 de mayo de 2004 (Vlex 414/2004) -siendo ponente ROMEO LORENZO- al establecer que:

"El hecho de que no quedara constancia escrita de la información no quiere decir que la misma no se haya facilitado, siempre que por otros medios se acredite la realidad de aquella» ${ }^{50}$.

De lo anterior se desprende que, aunque la actual normativa no impone como requisito de forma, la entrega de la información de forma escrita, lo cierto es que esta forma no está prohibida. De ahí que en la práctica la información que conste por escrito constituya un requisito de valor ad probationem ${ }^{51}$, y no ad solemnitatem en el sentido de que facilita la prueba de que existió tal información ${ }^{52}$.

${ }^{50}$ En idéntico sentido, entre otras, se han pronunciado las SSTS, Sala $3 .^{\text {a }}$, de lo Contencioso-Administrativo, Sección 6. ${ }^{\text {a }}$, de 3 de octubre de 2000 [Vlex 3905/1996] siendo ponente XIOL RÍOS-; de 18 de enero [Vlex 166/2004] y de 9 de mayo de 2005 [Vlex 3546/2001] -siendo ponente ROBLES FERNÁNDEZ-, y de 26 de enero de 2006 [Vlex 5681/2001] -del mismo ponente-, al no excluir de forma radical, la validez del consentimiento cuando la información no fuere brindada por escrito, siempre que la administración sanitaria hubiere probado por otros instrumentos o medios su existencia. También, la STS, Sala 1. ${ }^{\mathrm{a}}$, de lo Civil, de 10 de febrero de 2004 -siendo ponente CORBAL FERNÁNDEZ-, considera válido el consentimiento informado mediante la prueba de información confirmada por evidencias distintas a la constancia escrita en la historia clínica. Criterio que también ha sido sostenido por la jurisprudencia francesa, en este sentido, vid., la Sentencia de la Cámara 1. a , de lo Civil, de la Corte de Casación, de 4 de enero de 2005.

${ }^{51}$ En este sentido, la STS, Sala $1 .^{\text {a }}$, de lo Civil, de 29 de septiembre de 2005 [RJ 2005/8891]-siendo ponente SEIJAS QUINTANA, enjuicia la demanda interpuesta por una paciente intervenida de la rodilla derecha por padecer una displasia congénita bilateral de ambas rótulas, y que presentó tras la cirugía una mononeuropatia severa, tipo axonotmesis II-III, del ciático poplíteo externo, en sus dos ramas. La Sala declaró, en su fundamento de derecho tercero, que «la exigencia de la constancia escrita de la información tiene para casos como el que se enjuicia, mero valor ad probationem. La sentencia absolutoria dictada en la instancia es confirmada por el TS, al haber quedado acreditado por otros medios de prueba la existencia de la información y del consentimiento». En idéntico sentido, se pronunció la STS, Sala 1. a, de lo Civil, de 17 de noviembre de 2005 [RJ 2005/7636], también del mismo ponente.

${ }^{52}$ En este sentido, vid., entre otros, GALÁN CORTÉS, «Responsabilidad civil..., op. cit., págs. 539 y 540; ID: Responsabilidad civil..., op. cit., pág. 386; MARTÍNEZPEREDA RODRÍGUEZ, José Manuel. «Responsabilidad civil derivada de asistencia 
Tras la regla general en cuanto al consentimiento verbal, el artículo 8.2 de la Ley 41/2002, de 14 de noviembre, establece las excepciones en las que el consentimiento debe figurar por escrito. En concreto, el precepto reza en el siguiente sentido:

"El consentimiento será verbal por regla general. Sin embargo, se prestará por escrito en los casos siguientes: intervención quirúrgica, procedimientos diagnósticos y terapéuticos invasores y, en general, aplicación de procedimientos que suponen riesgos o inconvenientes de notoria y previsible repercusión negativa sobre la salud del paciente».

De modo que, en el caso de la anestesiología, dados los importantes riesgos que comporta todo acto anestésico, el consentimiento informado deberá prestarse siempre por escrito, debiendo ser incorporado este documento a la historia clínica, formando parte de su contenido mínimo, tal y como se desprende del artículo 15.2.i), conforme al cual:

«2. La historia clínica tendrá como fin principal facilitar la asistencia sanitaria, dejando constancia de todos aquellos datos que, bajo criterio médico, permitan el conocimiento veraz y actualizado del estado de salud. El contenido mínimo de la historia clínica será el siguiente: i) El consentimiento informado».

Por otra parte, en todos estos supuestos previstos por el artículo 8.2 resulta innegable que el deber de información del médico responsable es mucho más riguroso. De ahí que su contenido básico se encuentre regulado por el artículo 10 de dicho cuerpo legal, y en concreto, y para el caso de duda prevea en su apartado segundo que el consentimiento figure por escrito ${ }^{53}$.

médica», en SIERRA GIL DE LA CUESTA (coord.), Tratado de responsabilidad civil, Tomo II, Ed. Bosch, Barcelona, 2008, pág. 1089; BLANCO PÉREZ-RUBIO, Lourdes. «El deber de información en la medicina voluntaria o satisfactiva», en LLAMAS POMBO (Coord.), Estudios de Derecho de Obligaciones: Homenaje al Profesor Mariano Alonso Pérez, Vol. I, 2006, pág. 196.

${ }^{53}$ En este punto, conviene precisar que la doctrina -vigente el derogado artículo 10. 6 LGS- había llegado a parecidas conclusiones sobre la base de una interpretación estricta del concepto de «intervención» que el precepto utilizaba. Así, entre otros, vid., COBREROS MENDAZONA, Edorta. Los tratamientos sanitarios obligatorios y el derecho a la salud. Estudio sistemático de los ordenamientos italiano y español, Servicio Editorial de la Universidad del País Vasco, Bizcaia, 1988, págs. 283 y ss.; JORGE BARREIRO, Agustín. "Consentimiento informado y anatomía del paciente», en Revista Jano, Vol. XLVIII, núm. 1114, 1995, págs. 42 y ss.; GALÁN CORTÉS Responsabilidad civil..., op. cit., págs. 36 y ss.; SIMÓN, LOURDA, Pablo: El consentimiento informado, Ed. Triacastela, Madrid, 2000, págs. 211 y ss.; PALOMARES BAYO, Magdalena y LÓPEZ Y GARCÍA DE LA SERRANA, Javier. El consentimiento informado en la práctica médica y el testamento vital: Análisis de la legislación Europea, Nacional y Autonómica, Estudio de su evolución jurisprudencial, Ed., Comares, Granada, 2002, págs. 77 y ss. 
No obstante, a lo anterior, entendemos siguiendo a GALÁN CORTÉS que dicha precisión materializada en el artículo 10.2 resulta del todo innecesaria, debido a que toda intervención quirúrgica per se requiere del consentimiento escrito del paciente [art. 8.2] y, en consecuencia, a nuestro prudente entender, somos partidarios -apoyándonos en que su ubicación se encuentra en el apartado relativo al contenido de la información-, que habría sido más oportuno señalar que cuando más dudoso fuese el resultado de una intervención mayor fuese la información facilitada al paciente ${ }^{54}$.

Así, y por lo que aquí interesa, cuando más dudoso fuese el resultado, como sería el caso del acto anestésico o, cuanto menos necesaria terapéuticamente fuese una intervención, mayor debería ser la cantidad de información suministrada al paciente, relegándose a un rol secundario el consentimiento por escrito.

Una cuestión de interés que se ha suscitado respecto de la forma en que se pone a disposición del paciente la información, es la práctica, cada vez más habitual en el ámbito sanitario -conforme a la innumerable difusión de documentos o formularios de consentimiento informado que existen en los últimos tiempos-, de suministrársela mediante la utilización de protocolos o formularios informativos de carácter genérico, con la pretensión de facilitar la información y la prueba de la existencia del consentimiento.

Práctica que ha sido sumamente criticada tanto doctrinal como jurisprudencialmente en el entendido de que la finalidad perseguida por dichos formularios o protocolos genéricos de información radica, como norma general, en la protección del facultativo frente a posibles reclamaciones ulteriores ${ }^{55}$, despreocupándose de la auténtica información que debe ser facilitada al enfermo ${ }^{56}$.

${ }^{54}$ Responsabilidad civil..., op. cit., pág. 389.

${ }^{55}$ En este sentido, GARCÍA DE SOLA, Ricardo (en «El paciente como adversario», en Diario Médico, Sección de Normativa, 2004, pág. 10) señala que «los consentimientos informados son un documento con un contenido defensivo y no informativo-humano para el paciente».

${ }^{56}$ Vid., así, GALÁN CORTÉS. Responsabilidad civil..., op. cit., págs. 547 y 548; RODRÍGUEZ MARÍN, Concepción (en «Medicina satisfactiva», en ORTÍ VALLEJO (dir.), GARCÍA GARNICA (coord.), La responsabilidad civil por daños causados por servicios defectuosos. Estudio de la responsabilidad civil por servicios susceptibles de provocar daños a la salud y seguridad de las personas, Ed. Thomson Aranzadi, Pamplona, 2006, págs. 398 a 390) precisa que, mientras que en algunos casos, estos protocolos de consentimiento informado, específicos para determinadas patologías y debidamente personalizados, agilizan al facultativo su obligación de informar al paciente y a la par propician la ulterior obtención del consentimiento, en otros muchos casos, desvirtúan la auténtica finalidad de esta institución, debido a que su finalidad es la de proteger al facultativo frente a las posibles reclamaciones que pue- 
De esta forma, en muchas especialidades médicas, entre las que figuran con carácter especial aquéllas que podrían encuadrarse dentro de la denominada «medicina voluntaria o satisfactiva», se han ido elaborando formularios o protocolos que adaptados a cuantas peculiaridades pudieran derivarse de tales especialidades, tienen como finalidad recoger el consentimiento del paciente ${ }^{57}$.

Así, GALÁN CORTÉS precisa que «los documentos impresos de carácter genérico en modo alguno sirven, por consiguiente, para acreditar el cumplimiento de esta obligación por parte del facultativo, más bien al contrario, al igual que sucede con aquellos protocolos que carecen de la personalización necesaria ${ }^{58}$.

En suma, el consentimiento informado prestado a través de estos formularios tipos, es inválido porque no se entrega de forma adecuada la información al paciente y, es esta vulneración del deber de información la que acarrea como consecuencia la invalidación del consentimiento prestado a través de este medio.

En este sentido, la ya mencionada Sentencia del Tribunal Supremo, Sala 1. , de lo Civil, de 29 de mayo de 2003 (Vlex 511/1997) -siendo ponente VILLAGÓMEZ RODIL-, en su fundamento de derecho primero, con ocasión del fracaso de una esterilización tubárica dos años después de practicada, declaró que:

«El consentimiento prestado mediante documentos impresos carentes de todo rasgo informativo adecuado [...], ni conforma debida ni correcta información ${ }^{59}$.

También, se han pronunciado las Sentencias del Tribunal Supremo, Sala 1. ${ }^{a}$, de lo Civil, de 15 de noviembre (RJ 2006/8059) -siendo ponente SEIJAS QUINTANA- y de 26 de diciembre de 2006 -siendo del mismo ponente-, al precisar que los documentos tipos o genéricos de consentimiento informado constituyen una clara y evidente infracción del deber de información médica, concretamente, establecen que:

"Son documentos ética y legalmente inválidos que se limitan a obtener la firma del paciente, pues aun cuando pudieran proporcionar alguna información, no es la que interesa y exige la norma como razonable

dan acaecer, despreocupándose de la auténtica información que debe ser facilitada al enfermo.

${ }^{57}$ Así, RODRÍGUEZ MARÍN, op. cit., pág. 321.

${ }^{58}$ Responsabilidad civil..., op. cit., pág. 392.

${ }^{59}$ En la misma línea, vid., las SSTS, Sala 1. a de lo Civil, de 27 de abril de 2001 y de 26 de septiembre de 2000 -siendo ponente VILLAGÓMEZ RODIL-. 
para que conozca la trascendencia y alcance de su patología, la finalidad de la terapia propuesta, con los riesgos típicos del procedimiento, los que resultan de su estado y otras posibles alternativas terapéuticas [...]. Se trata de simples y escuetos formularios, más próximos a un mero acto administrativo, que médico [...]. Tampoco se hace mención particularizada de la situación médica del enfermo, ni concreción de los riesgos y posibles complicaciones de un tratamiento que no tenía carácter de urgencia y al que podía renunciar».

En idéntico sentido, se pronuncia la Sentencia del Tribunal Supremo, Sala 1. ${ }^{a}$, de lo Civil, de 20 de junio de 2006 (RJ 2006/5152), al negar validez a un documento inapropiado de consentimiento informado, con ocasión de la demanda interpuesta por la hija de una paciente que tras ser intervenida sufrió una perforación intestinal que le generó una peritonitis generalizada, falleciendo con posterioridad. El alto Tribunal, destacó en su fundamento derecho quinto, que:

"Un impreso de consentimiento informado en el que se habla de riesgos generales como infección o hemorragia, lesión nerviosa, hematomas, alteraciones cardiopulmonares, reacciones alérgicas y neumonías, pero que deja en blanco la casilla correspondiente a los riesgos personalizados respecto de la necesidad de utilizar otra técnica o procedimiento, no es específico para la intervención y, por tanto, el consentimiento dado por la paciente resulta incompleto, al desconocer los riesgos concretos de la operación quirúrgica a la que fue sometida la paciente».

También, en la Sentencia del Tribunal Supremo, Sala 1. , de lo Civil, de 11 de abril de 2014 (TOL3.706.415), -siendo ponente SEIJAS QUINTANA- se niega la validez a los documentos inapropiados de consentimiento informado, con ocasión de una intervención que se iba a realizar, tanto para la cirugía (cirugía de fracturas diafisarias (osteosintesis), aplicable al humero, cubito y radio, fémur y tibia), como para la anestesia, suscritas ambas por el paciente.

«los documentos se limitan a ser un impreso, en el que constan de una forma general y genérica los que se entienden como riesgos típicos de la intervención, mientras que el apartado correspondiente a riesgos personalizados, que habría de haberse dedicado a aquellos riesgos que se derivan de las condiciones peculiares de la patología o estado físico del sujeto, así como de sus circunstancias personales o profesionales relevantes, permanece en blanco, sin que conste observación alguna relativa a la patología previa» ${ }^{60}$.

${ }^{60}$ En este sentido, también en la STS, Sala $1 .^{\text {a }}$, de lo Civil, de 25 de septiembre de 2007 (TOL4.979.781), -siendo ponente XIOL RÍOS-, se niega validez al documento al tratarse de un documento tipo elaborado previamente y sin tener en cuenta la naturaleza y características propias del mismo. 
Por tanto, los documentos o formularios de consentimiento informado deben ser específicos y personalizados, por cuanto un formulario genérico de información no resulta válido a tales efectos, al no reunir los requisitos mínimos exigibles (especificidad, individualización [...]) para que el paciente pueda decidir, con suficiente conocimiento, si se somete o no a la intervención que el facultativo le propone, o si la pospone o acude a consultar con otro médico facultativo.

En concreto, la Ley 3/2005, de 8 de julio, de información sanitaria y autonomía del paciente de Extremadura, en su artículo 27.1 establece que:

"El documento de consentimiento deberá ser específico para cada intervención clínica, sin perjuicio de que se puedan adjuntar hojas y otros medios informativos de carácter general [...]».

Por otra parte, el artículo 4.2 de la Ley 41/2002, de 14 de noviembre, establece que:

"La información clínica forma parte de todas las actuaciones asistenciales, será verdadera, se comunicará al paciente de forma comprensible y adecuada a sus necesidades y le ayudará a tomar decisiones de acuerdo con su propia y libre voluntad».

GALÁN CORTÉS, precisa que «el médico deberá informar de manera objetiva, veraz, completa y asequible o, como ha reiterado la jurisprudencia francesa, de forma "simple, aproximativa, leal e inteligible», debiendo tener presente que la información excesiva y prolija, además de inútil en la mayoría de casos, puede ser perjudicial para el paciente» ${ }^{61}$.

Sobre esta materia, se han pronunciado las Sentencias del Tribunal Supremo, Sala 1. ${ }^{a}$, de lo Civil, de 10 de abril de 2004 -siendo ponente CORBAL FERNÁNDEZ- y de 26 de junio de 2006 -siendo ponente GONZÁLEZ POVEDA-, subrayando que:

"La necesidad de una información exhaustiva y suficiente de los riesgos que entrañe la actuación médica propuesta».

También, la mencionada Sentencia del Tribunal Supremo, Sala 1. ${ }^{a}$, de lo Civil, de 29 de mayo de 2003 (Vlex 511/1997) -siendo ponente VILLAGÓMEZ RODIL-, señala que la información al paciente:

«Ha de ser puntual, correcta, veraz, leal continuada, precisa y exhaustiva», debe pues tratarse, de una «información suficiente que permita contar con datos claros y precisos para poder decidir si se somete a la intervención que los servicios médicos le recomiendan o le proponen».

${ }^{61}$ Responsabilidad civil..., op. cit., pág. 396. 
Por su parte, han declarado las Sentencias del Tribunal Supremo, Sala 3. ${ }^{a}$, de lo Contencioso-Administrativo, Sección 6. ${ }^{a}$, de 3 de octubre de 2000 (Vlex 3905/1996) -siendo ponente XIOL RÍOS- y de 9 de mayo de 2005 (Vlex 3546/2001) -siendo ponente ROBLES FERNÁNDEZque:

"La información excesiva puede convertir la actuación clínica en desmesurada y en un padecimiento innecesario para el enfermo».

En el caso que nos ocupa, conviene precisar que en este ámbito de la anestesiología resulta necesaria la coordinación entre ambos facultativos -cirujano y anestesista- a la hora de informar al paciente sobre sus alternativas terapéuticas, conforme a la transcendencia que ostentan ambas informaciones en la decisión del paciente, debido como GALÁN CORTÉS y GALÁN GUTIÉRREZ precisan acertadamente a que:"[...] la opción inicialmente elegida tras la información brindada por el cirujano puede variar cuando el paciente tome en consideración aspectos de la anestesia que hasta entonces desconocía por no haber recibido aún la información personalizada por parte del médicoanestesista ${ }^{62}$.

En definitiva, en el caso del anestesista y conforme a los riesgos que presenta el acto anestésico, resulta necesario que el paciente obtenga una información vinculada y coordinada de ambas especialidades médicas, con la finalidad de decidir y reflexionar racionalmente sobre los diferentes tratamientos que puedan existir.

\section{II.4. El objeto del consentimiento y el contenido de la información}

El objeto del consentimiento informado se circunscribe a la específica intervención para la que ha sido otorgado, sin que, salvo caso de urgencia intercurrente y de actuación necesariamente inaplazable, sea extensible la actividad del facultativo a actuaciones ajenas a la inicialmente autorizada y que determinen la extracción, cercenamiento o lesión de cualquier otro órgano. De forma tal, que el facultativo no podrá realizar ninguna actuación médica que no se encuentre contemplada en el consentimiento previamente otorgado por el paciente, aunque pudiera beneficiarle.

Por cuanto atañe al contenido de la información, conviene precisar que se configura como uno de los aspectos más importantes, pues-

${ }^{62}$ Op. cit., pág. 97. 
to que puede condicionar la elección o el rechazo de una determinada terapia en atención a los riesgos que puedan dimanar de la misma, convirtiéndose en esencial la determinación del caudal informativo que ha de prestarse al paciente en cada caso concreto.

Asimismo, como ya se anunció en párrafos previos prudente es recordar que una información excesiva o innecesaria puede transformar la atención clínica en desmesurada y en un padecimiento innecesario para el paciente.

En este sentido, el artículo 5 del Convenio para la protección de los derechos humanos y la dignidad del ser humano con respecto a las aplicaciones de la Biología y la Medicina, establece que: «Una intervención en el ámbito de la sanidad sólo podrá efectuarse después de que la persona afectada haya dado su libre e informado consentimiento. Dicha persona deberá recibir previamente una información adecuada acerca de la finalidad y la naturaleza de la intervención, así como sobre sus riesgos y consecuencias».

Con la redacción de la nueva Ley 41/2002, de 14 de noviembre, conviene puntualizar dos aspectos. De una parte, que la acepción de «adecuada» utilizada por el mencionado Convenio la hace suya, al establecer en su artículo 2.2 con la categoría de principio básico, que: "Toda actuación en el ámbito de la sanidad requiere, con carácter general, el previo consentimiento de los pacientes o usuarios. El consentimiento, que debe obtenerse después de que el paciente reciba una información adecuada, se hará por escrito en los supuestos previstos en la Ley», corrigiéndose con ello la terminología utilizada por el derogado artículo 10.5 LGS, de tal forma que en la actualidad ya no se habla de «información completa», sino de «información adecuada», ajustándose más a las necesidades del paciente y a la realidad asistencial; Por otro lado, la reproducción parcial del tenor del artículo 5 del Convenio, al señalar en su artículo 4.1 que: «La información [...], comprende, como mínimo, la finalidad y la naturaleza de cada intervención, sus riesgos y sus consecuencias».

GALÁN CORTÉS señala que «el facultativo debe informar al paciente del diagnóstico y pronóstico de la enfermedad, de la forma y el fin del tratamiento, de las opciones o alternativas terapéuticas existentes, de las consecuencias seguras y posibles, de todas las circunstancias que puedan incidir razonablemente sobre la decisión del paciente como de la falta de medios del centro sanitario en el que se encuentra y de las consecuencias que para su salud tendría rechazar el tratamiento "63. Ade-

${ }^{63}$ Responsabilidad civil..., op. cit., pág. 405. 
más, y por los riesgos que comporta el acto anestésico, añade que «el médico-anestesista deberá informar, de forma adecuada a su paciente, de los riesgos de la anestesia y de las distintas alternativas (general, local, epidural [...]) para que el enfermo decida libremente su opción y sus riesgos, asumiendo todos ellos» ${ }^{64}$.

De lo anterior se desprende la necesaria coordinación que es requerida en el ámbito anestesiológico del cirujano y del anestesista a la hora de informar al paciente sobre todas las alternativas terapéuticas, dada la trascendencia de ambas informaciones en la decisión del paciente.

También, resulta necesario aludir, por la existencia de esta problemática en el ámbito de la anestesiología, en la información relativa a la falta de medios del centro asistencial, en particular, a la existencia de la unidad de reanimación o sala de despertar en la fase post-operatoria. Así, el artículo 12.2 de la Ley 4/2002, de 14 de noviembre, prevé que:

"Los servicios de salud dispondrán en los centros y servicios sanitarios de una guía o carta de los servicios en la que se especifiquen los derechos y obligaciones de los usuarios, las prestaciones disponibles, las características asistenciales del centro o del servicio, y sus dotaciones de personal, instalaciones y medios técnicos. Se facilitará a todos los usuarios información sobre las guías de participación y sobre sugerencias y reclamaciones».

Respecto a la información básica que debe facilitarse al paciente, con anterioridad a recabar su consentimiento escrito, el artículo 10.1 de la Ley 4/2002, de 17 de noviembre, incluye:

«El facultativo proporcionará al paciente, antes de recabar su consentimiento escrito, la información básica siguiente:

a) Las consecuencias relevantes o de importancia que la intervención origina con seguridad; $b$ ) Los riesgos relacionados con las circunstancias personales o profesionales del paciente; c) Los riesgos probables en condiciones normales, conforme a la experiencia y al estado de la ciencia o directamente relacionados con el tipo de intervención; d) Las contraindicaciones ${ }^{65}$.

Siguiendo el criterio de distintos autores, dicha información básica debería comprender también, además de las alternativas terapéuticas existentes, las consecuencias que podrían derivarse para el pa-

${ }^{64}$ «Responsabilidad civil..., op. cit., pág. 40.

${ }^{65}$ Así, entre otras, vid., la STS, Sala $3 .^{\text {a }}$, de lo Contencioso-Administrativo, Sección 6. ${ }^{a}$, de 29 de junio de 2011 [Vlex 497/2007] -siendo ponente MARTÍNEZ VARESGARCÍA. 
ciente en caso de rechazar la intervención propuesta o sus alternativas ${ }^{66}$, previsión que sí ha sido contenida por algunas legislaciones autonómicas ${ }^{67}$.

En el ámbito de la anestesiología la información que deberá básicamente suministrar el anestesista al paciente -salvo situaciones de excepción debidamente justificables- se concretan en las explicaciones (siempre accesibles al paciente) sobre el tipo de anestesia a utilizar y sus alternativas, para el supuesto que las hubiese; sus eventuales consecuencias, como los riesgos y efectos adversos de la administración del anestésico propuesto y, sus probabilidades de éxito o fracaso.

Respecto a la omisión de información sobre el tipo de anestesia a utilizar por el anestesista, se ha pronunciado, la ya mencionada Sentencia el Tribunal Supremo, Sala 1. ${ }^{a}$, de lo Civil, de 13 de abril de 1999 (RJ 1999/2583) -siendo ponente MARTÍNEZ-CALCERRADA GÓMEZ-, con ocasión de una intervención quirúrgica en la que el anestesista omitió la información pertinente tanto al paciente como en defecto a sus familiares respecto a cuál iba a ser la técnica anestésica a emplear, y como consecuencia de ello falleció el paciente -en este caso menor de edad-. El Tribunal falló en su fundamento de derecho sexto que:

"Se desprende una clara falta de información respecto a cuál iba a ser la técnica anestésica a emplear, pues no podemos olvidar que una de las obligaciones exigibles al profesional de la medicina y que forma parte de la lex artis ad hoc, es la de informar al paciente o en su caso, a los familiares del mismo, pues la falta de información previa a la familia, es tenida en cuenta hasta por la propia Sala que manifiesta su crítica [...] el derecho del paciente a ser informado no debe depender de la importan-

${ }^{66}$ En este sentido, vid., las amplias aportaciones de GALÁN CORTÉS Y GALÁN GUTIÉRREZ, op. cit., pág. 95 y, GALÁN CORTÉS, Responsabilidad civil..., op. cit., pág. 408.

${ }^{67}$ En este sentido, entre otras, la Ley 8/2003, de 8 de abril, sobre derechos y deberes de las personas en relación con la salud de Castilla y León, en su artículo 34 dispone que «El documento de consentimiento informado deberá ser específico para cada supuesto, sin perjuicio de que se puedan adjuntar hojas y otros medios informativos de carácter general. Dicho documento debe contener como mínimo:-Identificación y descripción del procedimiento, finalidad, naturaleza, alternativas existentes, contraindicaciones, consecuencias relevantes o de importancia que deriven con seguridad de su realización y de su no realización, riesgos relacionados con las circunstancias personales o profesionales del paciente y riesgos probables en condiciones normales conforme a la experiencia y al estado de la ciencia o directamente relacionados con el tipo de intervención». También, la Ley Foral 17/2010, de 8 de noviembre, de derechos y deberes de las personas en materia de salud en la Comunidad Foral de Navarra, en su artículo 49. 9. d) y f) prevé que: «-9. La información que se proporcione al paciente deberá incluir al menos:-d) Alternativas razonables al procedimiento; -f) Consecuencias previsibles de la no realización». 
cia que le dé un facultativo, y siendo, como es, un riesgo importante en las anestesias totales, la información debe ser requisito imprescindible».

Por su parte, en la Sentencia del Tribunal Supremo, Sala 3. ${ }^{a}$, de lo Contencioso-Administrativo, Sección 4. ${ }^{a}$, de 8 de marzo de 2011 (CJ 6162/2011) -siendo ponente LECUMBERRI MARTÍ-, se desestimó la responsabilidad del anestesista por omisión informativa, en el caso de una paciente a la que, antes de intervenir de hiperparatiroidismo, se la detecta en el pre-operatorio una enfermedad intersticial, información conocida y omitida por el anestesista, falleciendo la paciente días después de la intervención. En el asunto en autos, se indica que:

"es un hecho fijado por la Sala como consecuencia de la valoración de la prueba, que hubo una omisión informativa por el médico-anestesista que valoró la radiografía del tórax; ahora bien, esta omisión al ser intranscendente en el desarrollo y resultado de la intervención quirúrgica realizada, ni por la demora en la valoración de la radiografía y en la realización del correspondiente TAC, no puede ser determinante de una privación de expectativas, denominada por nuestra jurisprudencia de "falta de oportunidad» [...] que se concreta en que basta una cierta probabilidad de que la actuación médica pudiera evitar el daño, aunque no quepa afirmarlo con certeza para que proceda la indemnización por la totalidad del daño» [...] "Constituyendo el consentimiento informado un presupuesto o elemento esencial de la lex artis, al omitirse en la información suministrada a la paciente de un dato o elemento que no conllevaba un posible riesgo colateral de la operación, resultaba intranscendente en el supuesto contemplado en litis».

\section{II.4.1. La información sobre los riesgos del acto anestésico}

En el presente apartado se analiza la necesaria advertencia de las complicaciones, secuelas y demás efectos adversos -de carácter temporal o permanente- que se pueden originar con ocasión de la aplicación del acto anestésico, en una intervención quirúrgica.

En el caso del médico-anestesista, se ha planteado la cuestión de si el deber de información debe extenderse a todas las eventuales complicaciones o únicamente limitarse a las que constituyan riesgos típicos de la operación.

La solución a dicha cuestión ha planteado una amplia polémica en el ámbito doctrino-jurisprudencial, debido a la palpable oposición creada entre dos intereses que en apariencia se deducen inconciliables, de una parte, el deber jurídico de informar en relación con el procedimiento propuesto sobre los riesgos reales y potenciales que su 
aplicación comporta y sobre cuáles son las probabilidades de éxito o fracaso, con la finalidad de que la decisión adoptada por el paciente sea acorde con el ejercicio pleno de su derecho de autodeterminación; y de otra, la comprobación por parte del médico-anestesista de que existe cierto tipo de información que debido a las características que presenta el paciente puede ser inapropiada.

De forma tal que, si los riesgos son mínimos y sus ventajas muy críticas no parece oportuno ni justificado aumentar la preocupación del paciente facilitándole los eventuales riesgos de la intervención, debido a que ello podría originar que el paciente rechazase el procedimiento propuesto.

No obstante a lo anterior, conviene precisar conforme a los riesgos que comporta el acto anestésico, y con la finalidad de proteger los derechos de ambas partes -médico-anestesista y paciente-, que el especialista debería en todos los supuestos facilitar al paciente una información más exhaustiva, así como comentar con detalle, entre otras, las posibles complicaciones en caso de utilizar una técnica poco común o si utiliza un medicamento de reciente innovación en el mercado.

En este sentido, en la ya mencionada la Sentencia del Tribunal Supremo, Sala 1. ${ }^{a}$, de lo Civil, de 25 de abril de 1994 (Vlex 349/1994) -siendo ponente ALBACAR LÓPEZ-, se recoge, como uno de los componentes de la lex artis ad hoc, el derecho de información que debe proporcionar el anestesista, al establecer que:

"[...] debe informar al paciente [...] del diagnóstico de la enfermedad o lesión que padece, del pronóstico que de su tratamiento pueda normalmente esperarse, de los riesgos que del mismo, especialmente si éste es quirúrgico, puede derivarse [...]».

Sentadas las premisas anteriores, y en relación a la información que el facultativo debe entregar al paciente sobre los riesgos dimanantes de la intervención, en el apartado b) del referido artículo 10.1 se hace hincapié en la necesidad de informar de «los riesgos relacionados con las circunstancias personales o profesionales del paciente», cuando lo propio habría sido que se hiciese referencia a los riesgos relacionados con las circunstancias personales y profesionales, debido a que las circunstancias concretas de cada paciente, así como sus antecedentes clínicos requieren que se personalicen los riesgos que son intrínsecos a toda actuación médica.

En este sentido, la Sentencia del Tribunal Superior de Justicia, Sala de lo Contencioso-Administrativo de Galicia, de 24 de marzo de 2004 (núm. 848/2001) -siendo ponente GALINDO GIL-, condenó a la Con- 
sejería de Sanidad por los daños físicos y morales que sufrió una paciente que contrajo una infección nosocomial al ser operada de una artroplasia total de cadera derecha. El Tribunal, declaró que:

"Hubo un deficiente consentimiento porque la información que se dio a la enferma debía incluir los riesgos personalizados».

Por otra parte, el apartado c) del artículo 10.1 dispone la obligación de facilitar al paciente información «sobre los riesgos probables en condiciones normales, conforme a la experiencia y al estado de la ciencia o directamente relacionados con el tipo de intervención». Es decir, que incluye -aunque no utiliza una redacción clara- tanto los riesgos probables (o frecuentes), con independencia de su probabilidad o porcentaje de casos y los directamente relacionados con el tipo de intervención como los riesgos típicos, es decir, los específicos (o patognomónicos o previsibles) de la actuación concreta a realizar, con independencia de que su cuantificación estadística sea poco frecuente.

Así, FRANZKI establece que «el hecho de que determinados sucesos se produzcan de manera típica no implica que sucedan con una frecuencia numérica» ${ }^{68}$.

Por lo que a esta materia se refiere, la ya mencionada Sentencia del Tribunal Supremo, Sala 1. ${ }^{a}$, de lo Civil, de 12 de enero de 2001(TOL4 964.609) -siendo ponente MARTÍNEZ-PEREDA RODRÍGUEZ-, con ocasión de una lesión del nervio recurrente derecho en la cirugía vertebral cervical mediante la técnica de Cloward, lo que ocasionó a la paciente afonía y fonastenia, ha precisado que:

«La previsión nada tiene que ver con la frecuencia del suceso [...]; poco importa la frecuencia a efectos de la información y el tanto por ciento y las estadísticas al respecto, si es tal complicación inherente a toda intervención en el cuello, ya que por su inherencia y ser perfectamente conocida debió manifestárselo a la enferma».

Hay que tener presente que en el campo de la anestesiología cuando se hace referencia a los riesgos típicos, se alude a los específicos, propios e inherentes del acto anestésico, con independencia de su cuantificación estadística, quedando excluida de tal obligación de información respecto de los riesgos atípicos, es decir, de los eventuales, potenciales e imprevisibles, que no son inherentes a la intervención concreta y de los que no es obligatorio informar, debido a que no re-

${ }^{68}$ Die Beweisregeln im Arzthaftungsprozeb, Eine prozebrechtliche Studie unter Berücksichtigung des amerikanischen Rechts, Dunker \& Humblot, Belín, 1982, pág. 51. 
sulta exigible a los profesionales sanitarios informar de todos y cada uno de los potenciales o eventuales riesgos e infinitas complicaciones que del acto médico puedan originarse ${ }^{69}$.

Como ya hemos anunciado, somos partidarios de que el médicoanestesista ponga en conocimiento de su paciente con todo detalle las posibles complicaciones para el supuesto de que utilice una técnica poco común, o cuando se utiliza un medicamento nuevo, sobre todo cuando el estado físico del paciente presente un clara tendencia a que se le originen complicaciones o deba someterse a una intervención complicada y prolongada ${ }^{70}$.

Por otra parte, en caso de que exista una única opción terapéutica eficaz el médico-anestesista no quedará eximido de obtener el consentimiento informado previo a la práctica del acto anestésico, con la salvedad de supuestos de urgencia, debido a que de lo contrario se vulneraria el ya mencionado derecho de autodeterminación del paciente.

No obstante, como ya se anunció previamente, nuestro TS no es partidario de que al paciente se le facilite una información excesiva, debido a que podría convertir la actuación clínica en desmesurada y originar en el paciente un padecimiento innecesario ${ }^{71}$.

A mayor abundamiento, la Sentencia del Tribunal Superior de Justicia de Galicia, Sala de lo Contencioso-Administrativo, Sección 3. ${ }^{a}$, de 15 de febrero de 2000 (TOL2.442.645) -siendo ponente DE LOYOLA ARANGUREN PÉREZ-, precisó que:

"[...] sin que pueda confundirse ni mezclarse el consentimiento informado para una intervención quirúrgica con el requerido para la anestesia que responde a otros riesgos individualizados, específicos y distintos de los que soporta la intervención quirúrgica a la que sirve».

${ }^{69}$ En este sentido, GALÁN CORTÉS precisa que «la obligación de la información de la anestesia tiende en la sociedad francesa, a ser discutida en los Tribunales, especialmente para las llamadas "anestesias de confort», como la epidural. Así, el ejemplo típico que debe ser discutido con el paciente, para recabar su opinión y su ulterior autorización, viene recogido en una Sentencia de la Corte de Casación francesa, de 20 de marzo de 1984, en la que se reafirma la obligación de información del anestesista a un paciente, detallándose los riesgos previsibles de la anestesia» («Responsabilidad civil..., op. cit., págs. 1055 y ss.). También, la Sentencia de la Corte de Apelación de Montpellier, de 12 de julio de 1978, señala que «no es preciso informar más que de los riesgos previsibles de la anestesia». Por el contrario, la Sentencia de la Corte de Casación, Cámara 1. ${ }^{a}$, de 17 de noviembre de 1979, subraya la obligación de información del anestesista, incluso de los riesgos no frecuentes o encubiertos».

${ }^{70}$ Es de la misma opinión, DRIPPS, ECKENHOFF y VANDAM, op. cit., pág. 50.

${ }^{71}$ Así, entre otras, la STS, Sala 3. a , de lo Contencioso-Administrativo, Sección 6. ${ }^{a}$, de 3 de octubre de 2000 [Vlex 3905/1996] -siendo ponente XIOL RÍOS-.

(C) UNED. Revista de Derecho UNED, núm. 17, 2015 
Respecto a la omisión de la información sobre los riesgos propios del acto anestésico, resulta de interés la Sentencia del Tribunal Superior de Justicia de Murcia, Sala de lo Contencioso-Administrativo, Sección 1. ${ }^{a}$, de 5 de junio de 2009, con ocasión de la reclamación interpuesta por el marido de una paciente intervenida, bajo anestesia regional intravenosa, de una fractura-luxación de Monteggia del codo izquierdo. Se recoge la relación de hechos probados que:

«la paciente sufrió, en el curso de la intervención, una crisis de hipertensión arterial con cifras de 280/130 $\mathrm{mm}$ de $\mathrm{Hg}$, que se trató con hipotensores, descendiendo posteriormente la frecuencia cardiaca, por lo que fue preciso administrarle atropina intravenosa sin obtener respuesta, lo que condujo a un paro cardiaco en asistolia, que hizo necesario detener la cirugía para realizar maniobras completas de RCP avanzada, consiguiendo la recuperación de la función cardiaca, no obstante lo cual la paciente no recuperó el estado de vigilia como consecuencia de lesión por anoxia del tronco encefálico, falleciendo posteriormente por shock séptico [...]. La pericial practicada puso en evidencia que, dadas las características clínicas de la paciente, la técnica anestésica practicada era inadecuada, pues entre sus contraindicaciones se encuentra la hipotensión arterial severa, y esta paciente venía siendo tratada por este problema».

En relación con el documento de consentimiento firmado para la anestesia, la Sala refiere que:

"Éste era para anestesia general y no para loco-regional endovenosa. Simplemente se hizo una anotación señalando que si es posible se realizará con RIV, pero tampoco se hacían constar los riesgos concretos de esta técnica ni, por supuesto, la complicación que tuvo lugar y que, en definitiva, fue la causante del grave deterioro de la salud de la paciente y de su posterior fallecimiento" ${ }^{72}$.

En suma, se censura la omisión de información sobre los riesgos propios de la anestesia loco-regional practicada.

También, la Sentencia del Tribunal Supremo, Sala 3. ${ }^{a}$, Sección 4. , de 26 de marzo de 2012, con motivo de la reclamación formulada por

${ }^{72}$ También, sobre un supuesto de técnica anestesista inapropiada, se ha pronunciado STS, Sala $1 .{ }^{\mathrm{a}}$, de lo Civil, de 4 de junio de 2001 (TOL2.634.520) -siendo ponente MARÍN CASTÁN-, se condenó al médico-anestesista que intervino en la operación de un paciente que, tras ser intervenido para implantarle una prótesis de cadera izquierda, sufrió paralización de la pierna derecha y de los esfínteres y murió a causa de una tromboembolia pulmonar causada por la inmovilidad ciento catorce días después de la intervención, debido a una defectuosa administración de la anestesia epidural.

El Tribunal estimó que "por la evidencia de que antes de la intervención el paciente tenía sana su pierna derecha, ya que la prótesis de cadera se iba a implantar en la izquierda, y sin embargo la parálisis de aquélla se manifestó de forma inmediata a la intervención, siendo precisamente una de las complicaciones la técnica anestésica aplicada. Afirma, el nexo causal «entre la anestesia y la lesión»». 
los familiares de una joven primípara de veintitrés años, que falleció por shock cardiogénico tras la práctica de una cesárea, bajo anestesia intradural, en un centro sanitario público, ante la presencia de una enfermedad fetal del tipo crecimiento intrauterino retardado tipo II. La Sala declaró la responsabilidad de la Administración sanitaria por no haber obtenido el previo consentimiento informado para este tipo de anestesia, al considerar que:

"Resulta notorio (nueve posibilidades ofrece la hoja de enfermería circulante respecto del tipo de anestesia) que la anestesia intradural y la anestesia epidural no se llevan a cabo en los mismos espacios, intradural en el primer caso y epidural en el segundo, ni tampoco las mismas técnicas, por lo que no puede entenderse, salvo urgencia vital que no es el caso, que la una comprende a la otra, dadas sus distintas características y efectos (la Administración alegó que la paciente había firmado en una clínica privada el consentimiento informado para la analgesia epidural obstétrica y que, por tanto, era conocedora de sus riesgos; la Sala distinguió entre anestesia epidural e intradural, siendo esta última la aplicable a la fallecida y de la que se había omitido toda información a la misma)».

En definitiva, conforme a las peculiaridades que presenta el acto anestésico, el objeto del consentimiento informado quedará circunscrito a la específica intervención o técnica anestésica para la que haya sido otorgado; requerirá de un consentimiento informado específico y propio para esta técnica concreta, ya se trate de anestesia general o de otra modalidad anestésica y, además deberá estar coordinado con el de los demás profesionales que sean intervinientes en la operación que lo motiva y, se deberá informar de las distintas alternativas anestésicas existentes, contraindicaciones, riesgos típicos y probables; sin caer en una información excesiva que pueda generar en el paciente recelos o miedos y, en definitiva confundirlo.

Asimismo, y por cuanto atañe a la posible exigencia de la responsabilidad en que pueden incurrir estos facultativos resulta necesario tener en cuenta la imprevisibilidad derivada de las reacciones y sensibilidades del cuerpo humano.

En este sentido, la Sentencia del Tribunal Supremo, Sala 2. ${ }^{a}$, de lo Penal, de 22 de abril de 1988 -siendo ponente VIVAS MARZAL-, en su fundamento de derecho cuarto ha precisado que:

"es notorio que toda intervención quirúrgica, especialmente si se efectúa bajo los efectos de anestesia general, implica graves riesgos que la medicina y la cirugía no han podido, pese a los innegables progresos científicos, desarraigar, dándose un porcentaje sensible de fallecimientos consecutivos a dichas intervenciones, sucedidos, en ocasiones durante el tracto post-operatorio, como lo son la embolia postquirúrgica, la neumo-

(C) UNED. Revista de Derecho UNED, núm. 17, 2015 
nía hospitalaria, la vida vertiginosa de la tensión arterial, las hemorragias $u$ otros accidentes. Por ello, los facultativos deben extremar las cautelas y precauciones y emplear el instrumental de todas clases, adecuado y que se halle en condiciones óptimas de funcionamiento, preludiando la intervención con los indispensables análisis, radiografías y electrocardiogramas, tendentes a conocer el verdadero estado del paciente y a eliminar o, al menos, disminuir, las posibilidades de fracaso y de que se produzca un resultado letal».

Por tanto, los distintos riesgos derivados del acto anestésico no originan que la responsabilidad del anestesista sea objetiva ${ }^{73}$, sino que

${ }^{73}$ Así, vid., LLAMAS POMBO, op. cit., pág. 392 y, FERNÁNDEZ HIERRO, Sistema de responsabilidad..., op. cit., pág. 407. Desde el punto de vista jurisprudencial, la STS, Sala 1. a , de lo Civil, de 7 de febrero de 1990 -siendo ponente FERNÁNDEZ RODRÍGUEZ-, sostiene que con el recurso al riesgo -a la teoría del riesgo- se ha pretendido objetivar la responsabilidad; ahora bien, en la materia que nos ocupa, cabría afirmar que «la tesis del riesgo no es aplicable al ser inherente a las intervenciones quirúrgicas y además es aceptada como consustancial a ella en tanto no se acredite comportamiento doloso, culposo o negligente del médico interviniente y, por tanto, compartida y aceptada tanto por el médico como por el paciente que decide y accede someterse a ella». En el mismo sentido, las SSTS, Sala 1. ${ }^{\text {a }}$, de lo Civil, de 29 de marzo de 1994; de 25 de julio de 1996 y de 10 de noviembre de 1997. En jurisprudencia menor, la SAP de Tarragona, Sección 1. a , de 5 de enero de 2000 [AC 2000/713]-siendo ponente ALAVEDRA FARRANDO-, en su fundamento quinto, expuso que: "cuando el no resultado deseado no se acredita fuese debido a un comportamiento culposo o negligente en el actuar médico, sino a una imprevisible complicación surgida enteramente ajena al precitado médico actuante en la intervención quirúrgica de que se trata, y por tanto a la correcta intervención quirúrgica de que se trata y que le fue encomendada, lo que conduce a que no debe acogerse la presunción de responsabilidad formulada a medio de la demanda iniciadora del juicio de que se trata, y mayormente si se considera, de una parte, que la falta de prueba de culpabilidad así lo exige, en ortodoxa aplicación del principio de presunción de inocencia que consagra la Constitución en su art. 24 y que el Tribunal Constitucional en reiterado criterio aprecia aplicable no solamente al orden jurisdiccional penal, sino también al civil y otras materias, y de otra parte que la tesis del riesgo no es aplicable al ser inherente a las intervenciones quirúrgicas, y además es aceptada como consustancial a ella en tanto no se acredite comportamiento doloso, culposo o negligente del médico interviniente y, por tanto, compartida y aceptada tanto por el médico como por el paciente que decide y accede someterse a ella». Respecto a que dicha teoría no ha conseguido objetivizar la responsabilidad, la STS, Sala 1. ${ }^{\text {, }}$, de lo Civil, de 14 de abril de 2003 [RJ 2003/3706] -siendo ponente GARCÍA VARELA-, en su fundamento de derecho segundo, previó que: «[...] tras una adecuada exposición de los requisitos para la correcta aplicación del artículo 1902 del Código Civil, y un acercamiento a la llamada teoría de responsabilidad por riesgo, no ahonda ni en las tesis adecuadas al primero, en aplicación correcta de los artículos 1253 y 1104, pronunciándose en la culpa exclusiva de la víctima sin entrar ni motivar en la valoración del enlace evidenciado entre el hecho demostrado y el que se deduce a la luz de los preceptos infringidos- se desestima por las razones que se dicen seguidamente». También, la STS, Sala 1. ${ }^{a}$, de lo Civil, de 11 de junio de 2004 [RJ 2004/4639] -siendo ponente GARCÍA VARELA-, en su fundamento de derecho segundo, estableció que: «Esta Sala tiene declarado que "la tendencia jurisprudencial hacia una objetivación de la culpa extracontractual mediante los mecanismos de la inversión de la carga de la prueba y de la teoría del riesgo, no excluye de manera total y absoluta el esencial elemento psicológico 
exigen de una especial diligencia en la aplicación de la lex artis propia del médico anestesista-reanimador que comporte su minimización.

En particular, en la ya mencionada Sentencia del Tribunal Supremo, Sala 1. , de lo Civil, de 23 de marzo de 1993 (RJ 1993/2545) -siendo ponente GONZÁLEZ POVEDA-, en su fundamento de derecho octavo señaló que:

«La aplicación de la anestesia comporta riesgos y [...] los mismos pueden ser evitados adoptando las técnicas adecuadas, cuya simple existencia se encuentra basada en la realidad de tales riesgos y sobre su previsibilidad y evitabilidad».

Para finalizar, y en relación al recurso de las técnicas apropiadas a la lex artis, se ha pronunciado la ya mencionada Sentencia de la Audiencia Provincial de Asturias, Sección 6. ${ }^{a}$, de 5 de abril de 2000 (AC 2000/1508) -siendo ponente RODRÍGUEZ-VIGIL RUBIO-, en su fundamento de derecho tercero al descartar «cualquier idea de responsabilidad objetiva o por riesgos $»^{74}$.

\section{II.5. Momento en que debe prestarse el consentimiento informado por el paciente}

La doctrina es unánime en que el principio básico que rige en esta materia es el hecho de que la autonomía del paciente únicamente se verá respectada si se obtiene su consentimiento previamente a la intervención o al tratamiento médico de que se trate ${ }^{75}$.

De modo que aunque resulta evidente que el consentimiento del paciente debe ser prestado con anterioridad al acto médico que se

o culpabilístico, como inexcusable ingrediente integrador, atenuado pero no suprimido, de la responsabilidad por culpa extracontractual, de tal modo que si de la prueba practicada, con inversión o sin ella, aparece plenamente acreditado que en la producción del resultado dañoso, por muy lamentable que sea, no intervino ninguna culpa por parte del demandado o demandados, ha de excluirse la responsabilidad de los mismos», (STS de 28 de noviembre de 1998, y en el mismo sentido STS de 8 de marzo de 1999, entre otras), cuya doctrina es de aplicación para el decaimiento del motivo, toda vez que en la instancia aparece acreditada la falta de causalidad y, por consiguiente, de culpa de don Alberto en la efectividad del suceso del que resultaron lesiones para el demandante». En idénticos términos, las SSTS, Sala 1. ${ }^{a}$, de lo Civil, de 21 de diciembre de 2005 [RJ 2005/1047] -siendo ponente GONZÁLEZ POVEDA- y, de 16 de noviembre de 2006 [RJ 2006/8134] -siendo ponente SIERRA GIL DE LA CUESTA-.

${ }^{74}$ En doctrina, vid., FERNÁNDEZ HIERRO, Sistema de responsabilidad..., op. cit., p. 107.

${ }^{75}$ Así, RODRÍGUEZ MARÍN, op. cit., pág. 322.

(C) UNED. Revista de Derecho UNED, núm. 17, 2015 
pretende realizar ${ }^{76}$, lo cierto es que deberá subsistir durante todo el tratamiento (principio de temporalidad), de forma tal que se vaya modulando a lo largo de todo el proceso. De ahí que no se trate de un acto de tracto único, sino de tracto sucesivo o de ejecución continuada, planteándose en los distintos momentos a lo largo del proceso asistencial ${ }^{77}$. Por tanto, en aquellos supuestos en los que surjan modificaciones en el curso del tratamiento, el paciente deberá otorgar un nuevo consentimiento, debiendo el facultativo entregar una nueva información y esperar además un tiempo prudente para la toma de la decisión del paciente.

En este sentido, la Sentencia del Tribunal Superior de Justicia de Valencia, Sala Contencioso-Administrativo, de 28 de noviembre de 2003 (núm. 1566/2000), señaló que:

"La información es un proceso continuado que comprende desde el inicio hasta el final del tratamiento para que el paciente conozca su proceso en profundidad y le permita organizar y adecuar su conducta».

Téngase presente que nuestro ordenamiento jurídico sigue esta dirección, al señalar el artículo 2.2 de la Ley 41/2002, de 14 de noviembre, que: «Toda actuación en el ámbito de la sanidad requiere, con carácter general, el previo consentimiento de los pacientes o usuarios». Por su parte, el artículo 8.1 del mismo texto legal dispone que: «Toda actuación en el ámbito de la salud de un paciente necesita el consentimiento libre y voluntario del afectado, una vez que, recibida la información prevista en el artículo 4, haya valorado las opciones propias del caso».

${ }^{76}$ En este sentido, en la SAP de las Islas Baleares, Sección 4. ${ }^{\text {, }}$ de 13 de febrero de 2001 [Vlex 102/2001] -siendo ponente AGUILÓ MONJO-, se niega validez al documento de consentimiento firmado justo antes de entrar al quirófano. La Sala, señaló que «la información completa debe proporcionarse antes de que la voluntad se haya determinado en favor de la opción quirúrgica correctora, y ello no se consigue con el solo hecho de hacer firmar un escrito antes minutos antes de la operación y en circunstancias en las que, por razones sociológicas y personales, no se puede esperar del firmante una respuesta mediata y un consentimiento libremente expuesto». Las declaraciones de los testigos del paciente y la falta de pruebas que acreditasen lo contrario por parte del médico resultaron suficientes para que los jueces considerasen que la firma del documento se realizó minutos antes de la operación, pues los familiares aseguraron que "nunca hasta momentos antes de la intervención tuvieron conocimiento del documento de consentimiento informado".

${ }^{77}$ Así, GALÁN CORTÉS sostiene que «la información correcta concierne no solo a la fase previa a la celebración del contrato médico, sino también a la fase de ejecución del tratamiento, en cuanto permite al paciente consentir sobre la adopción de las medidas de precaución más idóneas para la salvaguarda de su salud» (Responsabilidad civil..., op. cit., pág. 380) y, vid., RODRÍGUEZ MARÍN, op. cit., pág. 319 y, las aportaciones a tal respecto de LIZZARAGA BONELLI, op. cit., pág. 281; BLANCO PÉREZ-RUBIO, La carga de la prueba ..., op. cit., pág. 55. 
En virtud de lo anterior se justifica la afirmación que sostiene que, la información ha de facilitarse con el tiempo suficiente para que el usuario pueda reflexionar y madurar su ulterior decisión.

En este sentido, GUERRERO ZAPLANA sostiene que «facilitar la información sin tiempo para prestar el consentimiento es tanto como privar de la información, pero sin embargo esta exigencia del tiempo no se ha tomado en suficiente consideración por el legislador para ofrecer al paciente la necesaria reflexión antes de consentir ${ }^{78}$.

También, GÓMEZ RIVERO señala que «el consentimiento se preste en un momento temporal que garantice la madurez de la decisión, debe tenerse presente que, en la medida de lo posible, el mismo habrá de obtenerse antes de que se presente el estado de sufrimiento que pueda alterar la capacidad de decisión del enfermo ${ }^{79}$.

En definitiva la falta de tiempo, ha determinado cierta controversia, a la que indudablemente no es ajena el anestesiólogo máxime cuando se encuentra en el quirófano con un paciente al que únicamente le han facilitado para su firma el documento de consentimiento informado de los riesgos de la anestesia poco antes de ser puesto a disposición de la intervención quirúrgica, es decir, sin prácticamente tiempo para madurar su decisión, lo que constituiría en caso de ser anestesiado, salvo caso de urgencia una mala praxis, con los consiguientes efectos que de la misma puedan derivarse ${ }^{80}$.

De las disposiciones de la Ley 41/2002, de 14 de noviembre, se desprende que la prestación previa del consentimiento, contempla como única salvedad el hecho de que el paciente se encuentre en una situación de urgencia, es decir, dentro de aquellos supuestos en los que concurran las notas de inmediatez y de gravedad, en los que no se precisa el consentimiento informado previo para realizar las actuaciones médicas o intervenciones clínicas indispensables en favor de la salud del paciente ${ }^{81}$.

${ }^{78}$ El consentimiento informado. Su valoración en la Jurisprudencia, Ed. Lex Nova, Valladolid, 2004, 4. ${ }^{\text {a }}$ ed., pág. 96.

${ }^{79} \mathrm{La}$ responsabilidad penal del médico, Ed. Tirant lo Blanch, Valencia, 2003, págs. 68 y 69.

${ }^{80}$ En este sentido, vid., las argumentaciones de GALÁN CORTÉS y GALÁN GUTIÉRREZ, op. cit., pág. 98.

${ }^{81}$ Así, el artículo 9. 2 en su apartado b) prevé que: «Los facultativos podrán llevar a cabo las intervenciones clinicas indispensables en favor de la salud del paciente, sin necesidad de contar con su consentimiento, en los siguientes casos: b) Cuando existe riesgo inmediato grave para la integridad física o psíquica del enfermo y no es posible conseguir su autorización, consultando, cuando las circunstancias lo permitan, a sus familiares o a las personas vinculadas de hecho a él». 
Por otra parte, resulta innegable que para que el consentimiento emitido por el paciente pueda tener la consideración de válido ${ }^{82}$, éste en el momento de otorgar el consentimiento deberá estar lúcido y consciente. Por ello, es necesario que el paciente preste el consentimiento antes de cualquier práctica médica, debido a que en ese momento se encontrará en estado de relativa claridad mental para comprender el alcance del acto que se realizará.

En este sentido, se ha pronunciado la Sentencia de la Audiencia Provincial de Ourense, Sección 1. ${ }^{a}$, de 8 de noviembre de 1997 (AC 1997/2311), -siendo ponente CRISTIN PÉREZ- ha señalado que

«La premedicación anestésica suele atenuar la capacidad de comprensión y decisión, no siendo por ello momento adecuado para recabar el consentimiento informado cuando el paciente se encuentre bajo los efectos de medicamentos».

Otra de las exigencias que configura el consentimiento informado se circunscribe al hecho de que éste debe ser actual, lo cual implica resaltar su carácter eminentemente temporal y revocable ${ }^{83}$. Así, la Ley 41/2002, de 14 de noviembre, en su artículo 8.5 prevé que: «El paciente puede revocar libremente por escrito su consentimiento en cualquier momento».

Téngase presente que la exigencia de la escrituración de dicho precepto únicamente es válida a efectos probatorios, por tanto, la revocación verbal ${ }^{84}$ tendría plena validez. Asimismo, en caso de consentimiento prestado con posterioridad a la práctica asistencial, resulta innegable que éste será ineficaz como tal, sin perjuicio de que pueda servir de ratificación del acto médico ya realizado ${ }^{85}$.

Por lo que, si la información no es transmitida con la antelación suficiente para el que el paciente pueda reflexionar adecuadamente, carecerá de validez y eficacia el consentimiento emitido aun en caso de que se encuentre firmado, por haberse actuado de forma contraria a los principios básicos que en éste deben concurrir y, constituyendo tal acto indudablemente una infracción de los derechos del paciente y, por tanto, de la lex artis formal, pudiendo ser determinante de responsabilidad del facultativo por los daños materializados tras su ac-

${ }^{82}$ En este sentido, GUERRERO ZAPLANA, considera que «proporcionar la información sin antelación suficiente para prestar el consentimiento equivale a no facilitar dicha información» (op. cit., pág. 96).

${ }^{83}$ Es de esta opinión, BILLANCETTI, Mauro: La responsabilitá penale e civile del médico, Cedam, Padova, 2005, 5. ${ }^{\mathrm{e}}$ ed., pág. 352.

${ }^{84}$ Vid., entre otros, DOMINGO LUELMO, Derecho sanitario..., op. cit., pág. 309; RODRÍGUEZ MARÍN, op. cit., pág. 363.

${ }^{85}$ Así, LÓPEZ MESA, op. cit., pág. 363. 
tuación, aun a pesar de que hubiese mediado - por su parte- una actuación correcta desde el punto de vista técnico.

En definitiva, el consentimiento del paciente al acto anestésico debe ser expresado antes de la administración de la medicación preanestésica, con la finalidad de que resulte asegurada la plena eficacia del acto $^{86}$.

Desde el punto de vista jurisprudencial, aunque sobre dicha cuestión se han pronunciado en escasas ocasiones, lo cierto es que han adoptado una posición de unanimidad, al exigir que la información sea otorgada al paciente con la antelación debida para que éste pueda ejercer su derecho de autodeterminación.

Por lo que a esta materia se refiere, la Sentencia del Tribunal Supremo, Sala 1. ${ }^{a}$, Sección Única, de 22 de julio de 2003 (Vlex 783/2003) -siendo ponente VILLAGÓMEZ RODIL-, con ocasión de una cirugía estética mamaria en la que la información no se facilitó de forma adecuada y suficiente, señaló que:

"Se infringió el deber de información [...], pues no se trata de una información oportuna y efectiva, ya que no consta acreditado que se hubiera realizado con una inmediatez temporal razonable a la operación, lo que era carga probatoria del médico demandado» ${ }^{87}$.

También la jurisprudencia menor mantiene idéntico criterio. En particular, la Sentencia de la Audiencia Provincial de las Islas Baleares, Sección 4. a de 13 de febrero de 2001 (Vlex 102/2001) -siendo ponente AGUILO MONJO- dejó sin efecto el consentimiento informado pres-

${ }^{86}$ Por su parte, SNOW es partidario de obtener el consentimiento escrito del paciente durante la visita pre-operatoria que, como norma general se verifica la víspera del día establecido para la intervención (op. cit., págs. 40 y ss.).

${ }^{87}$ En este sentido, RIBOT IGUALADA, Jordi (en "Comentario a la STS, de 22 de julio de 2003. Cirugía estética. Intervención quirúrgica correctora de mamas con resultado de cicatrices antiestéticas. Responsabilidad contractual del cirujano», en CCJC, núm. 64, 2004, pág. 415) precisa que «en aquellos supuestos en que se presuma que el paciente dispone de una información adecuada -por haberse sometido con anterioridad a idéntica prueba o intervención-, el médico ostentará la carga de comprobar que el paciente dispone de esa información razonable, de tal forma que si así no fuere la complemente en la medida en que resulte necesario». Desde el punto de vista jurisprudencial, la STS, Sala 1. ${ }^{a}$, de lo Civil, de 2 de julio de 2002 [TOL202.422] -siendo ponente CORBAL FERNÁNDEZ-, con ocasión de una operación de vasectomía, y debido a complicaciones surgidas en la misma se produjo al paciente un gran hematoma que acarreó la pérdida por atrofia de uno de los testículos, precisó que: «se infringió el deber de información médico, de tal modo que el consentimiento obtenido para la operación no estaba debidamente informado por lo que el paciente (cliente o usuario) no pudo ejercitar con cabal conocimiento (consciente, libre y completo) el derecho a la autonomía decisoria que tiene su fundamento en la dignidad de la persona». 
tado por la paciente al entender que carece de validez por haber sido firmado, prácticamente, a las puertas del quirófano, porque:

«La información debe darse con la antelación necesaria para que la voluntad se determine libremente [...]la información completa debe proporcionarse antes de que la voluntad se haya determinado en favor de la opción quirúrgica correctora y que ello no se consigue por el solo hecho de hacer firmar un escrito minutos antes de la operación y en circunstancias en las que, por razones obvias sociológicas y personales o individuales, no se puede esperar del firmante una respuesta mediata o un consentimiento libremente expuesto, especialmente cuando quien ofrece el documento a la firma no es el médico o cirujano que debe realizar la operación».

En idéntico sentido, la Sentencia de la Audiencia Provincial de León, Sección 3. ${ }^{a}$, de 5 de septiembre de 2006 (Vlex 167/2006)-siendo ponente ROBLES GARCÍA-, consideró que los consentimientos informados prestados por la enferma carecían de validez por haber sido firmados el mismo día de la intervención, debido a que se privó a la enferma de la posibilidad de poder desistir de la intervención, al no conocer todos los efectos que de aquélla podían derivarse.

En la misma línea, la Sentencia del Tribunal Superior de Justicia Extremadura (Cáceres), Sala de lo Contencioso-Administrativo, de 15 de mayo de 2008 (Vlex 65/2008) -siendo ponente DOMÍNGUEZ CALVOdeclara sobre la necesaria antelación de la firma del documento de consentimiento informado, que:

"El documento es firmado cuando la paciente se encuentra ingresada en el Hospital, el día antes de la operación, sin que exista constancia, por consiguiente, si fue debidamente informada, verbalmente o por escrito $y$ con la suficiente antelación, de los riesgos, beneficios, alternativas, pronostico y diagnóstico de la intervención, pues la información debe ser continuada y no ofrecerse únicamente cuando ya el paciente ha ingresado en un centro con la finalidad de ser sometido a dicha operación, pues las alternativas de elección que tiene en tal momento son lógicamente inferiores. $Y$ es que, no debemos olvidar, como ha afirmado con reiteración el TS, que solo mediante un protocolo, amplio y comprensivo de las distintas posibilidades y alternativas, seguido con especial cuidado, puede garantizarse que cumpla su finalidad. Entendemos, por consiguiente, que al no ir precedido de la debida información en este caso concreto el consentimiento, teniendo en cuenta sobre todo la especial situación personal de la actora, no puede considerarse válido y eficaz, y por ello, existe un incumplimiento de la lex artis ad hoc por parte de los profesionales médicos».

En este sentido, como XIOL RÍOS y BASTIDA FREIJEDO ${ }^{88}$, acertadamente, precisan la jurisprudencia sostiene, de forma pacífica y

${ }^{88}$ Autonomía del paciente, responsabilidad patrimonial y derechos fundamentales, Vol. I, Ed. Fundación Coloquio Jurídico Europeo, Madrid, 2012, 1. a ed., pág. 45. 
uniforme, que la información debe hacerse efectiva con tiempo, antelación y dedicación suficiente.

En síntesis, en el ámbito de la anestesiología, esta antelación suficiente a la que alude nuestra jurisprudencia, indudablemente estará en función de las circunstancias de cada caso concreto, tanto del paciente como de acto anestésico concreto a aplicar. De ahí que fijar un tiempo previo mínimo y uniforme para todos los supuestos será complejo y difícil, aun a pesar de que algunas legislaciones autonómicas lo han establecido en 24 horas.

Por último, conviene destacar que frente a la inexistencia por la normativa nacional de regulación expresa del periodo mínimo de reflexión que debe mediar entre la entrega de información y la manifestación del consentimiento por el paciente, algunas disposiciones autonómicas -como analizaremos en las próximas líneas- sí han señalado que la información se deberá facilitarse con una antelación suficiente para que el paciente pueda reflexionar con calma y decidir libremente.

\section{II.5.1. Referencia a la legislación autonómica}

Como ya se ha mencionado puntualmente, algunas legislaciones autonómicas, han abordado con detalle este presupuesto del consentimiento informado, dada su gran transcendencia, pero lo cierto es que no lo han hecho de forma homogénea originado con ello la existencia de diferencias inter-autonómicas considerables. Así, entre otras:

La Ley 3/2001, de 28 de mayo, reguladora del consentimiento informado y de la historia clínica de los pacientes de la Comunidad Autónoma de Galicia (modificada por Ley 3/2005, de 7 de marzo, de modificación de la Ley 3/2001, de 28 de mayo, reguladora del consentimiento informado y de la historia clínica de los pacientes) prevé al respecto en su artículo 8.3, que: «La información se facilitará con la antelación suficiente para que el paciente pueda reflexionar y decidir libremente».

También en idéntico, sentido la Ley $8 / 2003$, de 8 de abril, sobre derechos y deberes de las personas en relación con la salud, de la Comunidad Autónoma de Castilla y León, incide en esta circunstancia con la pretensión de garantizar la efectividad real del derecho a la información y evitar su conversión en un simple formalismo, previendo en su artículo 17.3 que: "La información se facilitará en términos 
comprensibles, adecuados a las necesidades de cada persona y con antelación suficiente para que ésta pueda reflexionar y elegir libremente» ${ }^{89}$.

De lo anterior, se desprende que la información recibida tiene que permitir reflexionar al paciente, y fruto de dicha reflexión, decidir. Por tanto, únicamente si existe posibilidad de reflexión y, en consecuencia, de decisión, se podrá entender que la información ha sido transmitida con la «antelación suficiente».

Lo anterior parte de la premisa de que en esa «antelación suficiente» hay tranquilidad y calma recíproca en ambas partes, es decir, tanto en el facultativo que transmite la información como en el paciente que la recibe.

Por tanto, como ABEL LLUCH acertadamente precisa la antelación suficiente «permite la maduración de la decisión y eventualmente una segunda opinión médica» ${ }^{90}$.

Ayuda a matizar qué debe entenderse por «antelación suficiente» acudir, entre otras, legislaciones autonómicas a lo dispuesto en el artículo 43. 9 de la Ley 10/2014, de 29 de diciembre, de la Generalitat, de Salud de la Comunitat Valenciana, precepto que reza en el siguiente sentido: «La información previa al consentimiento se facilitará con la antelación suficiente y, en todo caso, al menos 24 horas antes del procedimiento correspondiente, siempre que no se trate de actividades urgentes ${ }^{91}$.

${ }^{89}$ También hacen alusión a la «antelación suficiente»: La Ley 5/2010, de 24/06/2010, sobre derechos y deberes en materia de salud de Castilla-La Mancha, en su artículo 9. 4 establece que: "La información, como regla general, se proporcionará al paciente verbalmente, dejando constancia escrita en la historia clínica. Esta información deberá darse de forma comprensible, adaptada a la capacidad de cada persona, de manera continuada y con antelación suficiente a la actuación asistencial para permitir a la persona elegir con libertad y conocimiento de causa»y, el Decreto 38/2012, de 13 de marzo, sobre historia clínica y derechos y obligaciones de pacientes y profesionales de la salud en materia de documentación clínica de la Comunidad Autónoma del País Vasco, en su artículo 25.3 dispone, que: «Se facilitará con antelación suficiente, y en todo caso, al menos 24 horas antes del procedimiento correspondiente, siempre que no se trate de actividades urgentes».

90 «El derecho de información del paciente como presupuesto del consentimiento informado. Su régimen jurídico en la Ley 41/2002, de 14 de noviembre, básica reguladora de la autonomía del paciente y de derechos y obligaciones en materia de información y documentación clínica», en Cuadernos de derecho judicial, núm. 10, 2004, pág. 110 .

${ }^{91}$ También, el Decreto 38/2012, de 13 de marzo, sobre historia clínica y derechos y obligaciones de pacientes y profesionales de la salud en materia de documentación clínica de la Comunidad Autónoma del País Vasco, en su artículo 25.3 hace referencia a las 24 horas. 
En virtud de lo anterior, se desprende que indudablemente no existiría antelación suficiente si no hubo condiciones o tiempo para dicha reflexión, o aunque lo hubiese habido, por el momento en que esa reflexión se produce, ya no cabe elección.

En este punto, es conveniente traer a colación la ya mencionada Sentencia de la Audiencia Provincial de Barcelona, Sección 17. ${ }^{a}$, de 30 de septiembre de 2005 (La Ley Juris: 613778/2006)-siendo ponente MONTOLIO SERRA-, en la que se hace responsable civilmente al anestesista por su conducta no acorde con la praxis médica que se le puede exigir, debido a la incorrecta realización de la evaluación preanestésica $^{92}$.

También, en el Auto del Tribunal Supremo, Sala 1. , de lo Civil, de 22 de septiembre de 2009 (Vlex 1741/2007) -siendo ponente XIOL RÍOS-, se hace responsable civilmente al anestesista por la punción practicada para anestesiar a la paciente, debido a que no se adoptaron al efecto cautelas previas, mediante consulta de pre-anestesia o la realización previa de las pruebas oportunas para descartar en su caso la realización de la técnica anestésica que se utilizó.

Téngase presente que esta evaluación pre-anestésica, junto con la per-anestesia y la post-anestesia, es uno de los componentes que constituyen la actividad anestésica ${ }^{93}$, por tanto, esa evaluación formará parte de la conducta o lex artis que se le reclama al médico anestesista.

En el asunto en autos, el anestesista reconoció que no le pidió al paciente «un consentimiento informado especial para el acto anestésico, que no le dio ninguna medicación pre-anestésica, ni le hizo más visita que la realizada a la entrada al quirófano »94,

${ }^{92}$ En idéntico sentido, se han pronunciado las SSAAPP de Guipúzcoa, Sección 3. ${ }^{a}$, de 19 de diciembre de 2013 [TOL4.361.558] -siendo ponente BILDARRAZ ALZURIy, de Córdoba, Sección, 1. ${ }^{\mathrm{a}}$, de 8 de junio de 1997 [TOL1.625.220] -siendo ponente MAGAÑA CALLE-, en las que se indica que los patrones a que debe ajustarse la actuación del médico anestesista (evaluación pre-anestésica, per-anestesia con presencia continua durante la intervención quirúrgica y permanente evaluación monitorizada, y post-anestesia mediante control del paciente en la unidad de recuperación), confirmando en el caso la condena del demandado por haberse omitido las pruebas previas a la intervención.

${ }^{93}$ Así se encuentra recogido: -1. De forma genérica, en la Guía de Formación de especialidades en Anestesiología y Reanimación del Consejo Nacional de especialidades médicas. -2. De modo más detallado en la Guía de Práctica clínica en Anestesiología y Reanimación de la SEDAR.

${ }^{94}$ En idénticos términos, en la SAP de Barcelona, Sección 17. ${ }^{\text {a }}$, de 30 de septiembre de 2005 [La Ley Juris: 613778/2006] -siendo ponente MONTOLIO SERRA-, el anestesista reconoció que "no va demanar al pacient un consentiment informat especial per l'acte anestèsic, que no li va donar cap medicació pre-anestèsica ni va fer més visita al pacient que aquella que va fer a l'avant-quiròfan». Trad.: "no le solicitó al pa-

(C) UNED. Revista de Derecho UNED, núm. 17, 2015 
Por tanto, realizó la evaluación pre-anestésica minutos antes de que el paciente ingresase en el quirófano, cuando lógico habría sido mantener una entrevista con la que la anestesista se hiciese cargo de la situación del paciente para poder informarme debidamente ${ }^{95}$. Información anticipada con la que el paciente podría haber reflexionado y elegido libremente y que le habría permitido prestar un consentimiento más informado.

Asimismo, conviene precisar que la información que se debe prestar con antelación es la referida a la actuación a realizar, es decir, la de esa actuación en ese preciso momento, por tanto, no será válida la información prestada para una actuación idéntica, pero anterior en el tiempo, que no se llegó a realizar.

En suma, resulta innegable la imposibilidad de alusión alguna a «antelación suficiente» cuando al paciente se le informa en un primer momento y con la información recibida decide no intervenirse. Si en un momento posterior pretende la intervención previa, lo preceptivo será volver a informarle ${ }^{96}$.

ciente un consentimiento informado especial por el acto anestésico, que no le dio ninguna medicación anestésica ni más visita al paciente que aquélla que realizó antes del quirófano».

${ }_{95}$ Se parte de la premisa de que es preceptiva, como parte de esa correcta información, la comunicación al paciente de la anestesia que se le va a aplicar y de los riesgos post-operatorios, así se desprende de las SSAAPP de Girona, Sección 1. ${ }^{\text {a }}$, de 24 de febrero de 2000 [Vlex 97/2000] -siendo ponente PÉREZ CAPELLA- y, de Córdoba, Sección $3{ }^{\mathrm{a}}$, de 29 de enero de 2001 [Ley Juris 531/2001] -siendo ponente MORENO GÓMEZ- en las que con carácter preoperatorio, se solicitó que se informara a la paciente de la anestesia que se le aplicaría y de los riesgos post-operatorios, dada su especial constitución, y las dificultades de la punción intradural. También, en la SAP de Barcelona, Sección 1. a , de 6 de junio de 2007 [TOL1.150.766] -siendo ponente PORTELLA LLUCH-, se condena al anestesista por prestar insuficiente información sobre de los riesgos de la aplicación anestésica a la intervención de la paciente. También en la STSJ de las Islas Baleares, Sala de lo Contencioso-Administrativo, de 2 de marzo de 2015 [Vlex 134/2015] -siendo ponente ORTUÑO RODRÍGUEZ- se hace alusión a un caso en el que la paciente no fue lo suficientemente informada de los riegos derivados de la técnica anestésica a utilizar en la cesaría y en el subsiguiente tratamiento profiláctico, derivándose un resultado dañoso (el hematoma subaracnoideo, con subsiguiente paraplejia) de la aplicación de la técnica de anestesia intrarraquídea.

${ }^{96}$ Así, la STS, Sala 1. , Sección, Única, de 22 de julio de 2003 [Vlex 783/2003] siendo ponente VILLAGÓMEZ RODIL-, se estableció que «se produjo suficiente información previa, respecto al proceso quirúrgico a desarrollar para mejorar el estado de las mamas, con indicación de los riesgos y secuelas posibles, de modo que la paciente en aquella época, tras valorar la información recibida, decidió no intervenirse por el momento. [...] Se trata por tanto de una información anterior, admitiendo su existencia, pero no una información actualizada, puntual y precedente a la intervención». El Tribunal, declaró que «no procede admitir que la información anterior resulte vigente y eficaz y pueda proyectarse a la operación que es objeto de este proceso, sobre todo cuando como respuesta a aquella la recurrente decidió no operarse». 
En definitiva, la información proporcionada por el facultativo deberá serlo para cada intervención, de ahí que no sea comprensible que la ya facilitada con antelación sea suficiente, por causa de la realización de una intervención previa.

En este punto, la Sentencia de la Audiencia Provincial de Murcia, de 26 de febrero de 2003 (JUR 2003/196801) -siendo ponente DÍAZ SUAREZ-, estableció en su fundamento derecho tercero, que:

"El correcto cumplimiento de ese deber de información no puede inferirse de una intervención anterior que, por sí sola, no puede eximir o resignar su cumplimiento, ni eleva unos niveles de información contrariamente influidos por la confianza, ni es tampoco factor de aminoración de riesgos que a menudo se incrementan con la reiteración de actividades clínicas».

Otra cuestión de gran interés que se desprende de la literalidad que presentan los textos contenidos en las legislaciones autonómicas mencionadas, se circunscribe al hecho de que esa antelación suficiente, que permite reflexionar y elegir al paciente, requiere de tiempo. Y en este sentido, se plantea la cuestión de qué antelación se tendrá por suficiente en un supuesto de urgencia, en el que no se permita demora alguna frente a la posibilidad de originar lesiones irreversibles o de existir un serio peligro de fallecimiento del paciente.

Frente a dicha cuestión se puede concluir que de igual manera que en este caso no es necesario el consentimiento previo y por escrito del paciente, también debería entenderse que la información no debería ser conocida directamente por el paciente, siendo suficiente con que se le intente comunicar lo que permitan sus circunstancias y grado de comprensión, con la antelación -que en el caso de urgencia- la situación reclama.

Partiendo de la premisa de que en estos supuestos la lex artis en la actuación exige urgencia más que cumplir con las pautas de la información, se puede sostener la teoría de que se mantiene ese deber de información, pero indudablemente, sobre éste prima la situación de urgencia en la atención médica, de ahí que nada impida que se cumpla con dicho deber neutralizada la situación urgente, es decir, en un momento posterior ${ }^{97}$.

Además, el referido precepto contenido en la Ley 10/2014, de 29 de diciembre, de la Generalitat, de Salud de la Comunitat Valenciana (en

${ }^{97}$ En este sentido, vid., BERROCAL LANZAROT, Ana Isabel: «El consentimiento informado y capacidad del paciente para prestarlo válidamente en la nueva ley 41/2002, de 14 de noviembre», en Anuario de Derechos Humanos, núm. 5, 2004, pág. 48. 
idénticos términos, se ha pronunciado la Comunidad Autónoma de Extremadura en el artículo 28. 3 de la Ley 3/2005, de 8 de julio, de información sanitaria y autonomía del paciente) también dispone en qué momentos no se debe facilitar la información, ya por circunstancias personales del paciente, que llevan a que no sea el momento más idóneo para informarle, o por circunstancias temporales que no le permiten ponderar la información recibida, así el precepto prevé que: "En ningún caso se dará información al paciente cuando esté adormecido ni con sus facultades mentales alteradas, ni tampoco cuando se encuentre ya dentro del quirófano o la sala donde se practicará el acto médico o el diagnóstico».

En este sentido, téngase presente que la referencia realizada en el articulado contenido tanto por la Ley 10/2014, de 29 de diciembre, como por la Ley 3/2005, de 8 de julio, respecto de que en ningún caso se dará información al paciente cuando esté adormecido ni con sus facultades mentales alteradas, ni tampoco cuando se encuentre ya dentro del quirófano o la sala donde se practicará el acto médico o el diagnóstico, resulta del todo innecesaria, ya que la obtención del documento de consentimiento formal en dicho estado, carecería de validez, debido a que con dicha actuación no se garantiza el derecho de autodeterminación del paciente, que indudablemente requiere de una información adecuada y de un tiempo para su reflexión.

Así, la Sentencia de la Audiencia Nacional, Sala de lo ContenciosoAdministrativo, Sección 4. ${ }^{a}$, de 25 de febrero de 2004 (núm. 386/2002) -siendo ponente GUERRERO ZAPLANA-, con ocasión de la reclamación efectuada por los familiares de un paciente que falleció a los dos días de practicada una colangiopancreatografía retrógrada con fines diagnósticos, señaló que:

"No hay duda, que el respeto de los derechos del paciente (reconocidos ahora con más detalle por la Ley 41/2002, que no estaba vigente a la fecha en que se recurrieron los hechos) no puede permitir que se considere suficiente una información que se pudiera haber producido en el interior de la Sala de Endoscopias y ello pues una información prestada en tales condiciones habría supuesto una clara infracción de los derechos del paciente, al presuponer la realización de la información sin atender a las exigibles condiciones de estabilidad y seriedad en la prestación del consentimiento, al haberse informado de forma claramente contraria a los principios básicos sobre la cuestión que se recogen, fundamentalmente, en los artículos 4.2 y 10 de la referida Ley».

Por último, la Ley 3/2009, de 11 de mayo, de los Derechos y Deberes de los Usuarios del Sistema Sanitario de la Región de Murcia, en su artículo 43. 1 dispone que: «La información previa al consentimien- 
to informado, que debe ser comprensible y suficiente, se ofrecerá al paciente, salvo en supuestos de urgencia, con la debida antelación y preferentemente no en la misma sala en donde se deba practicar la actuación asistencial, a fin de que el paciente pueda reflexionar y, en su caso, solicitar cuantas aclaraciones considere necesarias para adoptar una decisión».

En virtud de lo anterior, podemos precisar que nos encontramos ante distintas regulaciones, de forma tal que se pierde la uniformidad que debería presidir una cuestión de semejante índole e importancia en el ámbito sanitario. 
